This item was submitted to Loughborough's Research Repository by the author.

Items in Figshare are protected by copyright, with all rights reserved, unless otherwise indicated.

\title{
Systematic model identification and optimization-based active polymorphic control of crystallization processes
}

PLEASE CITE THE PUBLISHED VERSION

https://doi.org/10.1016/j.ces.2017.09.034

\section{PUBLISHER}

(C) Elsevier

VERSION

AM (Accepted Manuscript)

\section{PUBLISHER STATEMENT}

This work is made available according to the conditions of the Creative Commons Attribution-NonCommercialNoDerivatives 4.0 International (CC BY-NC-ND 4.0) licence. Full details of this licence are available at: https://creativecommons.org/licenses/by-nc-nd/4.0/

\section{LICENCE}

CC BY-NC-ND 4.0

\section{REPOSITORY RECORD}

Simone, Elena, Botond Szilagyi, and Zoltan K. Nagy. 2018. "Systematic Model Identification and Optimizationbased Active Polymorphic Control of Crystallization Processes". figshare. https://hdl.handle.net/2134/36124. 
1 Systematic model identification and optimization-based active polymorphic

\section{control of crystallization processes}

\author{
E. Simone ${ }^{1,2}$, B. Szilagyi ${ }^{2,3}, \underline{\text { Z.K. Nagy }}{ }^{2,3 *}$ \\ ${ }^{1}$ School of Food Science and Nutrition, University of Leeds, Leeds, LS2 9JT, UK \\ ${ }^{2}$ Department of Chemical Engineering, Loughborough University, Loughborough, LE11 \\ 3TU, UK; \\ ${ }^{3}$ Davidson School of Chemical Engineering, Purdue University, West Lafayette, IN 47907- \\ 2100, USA \\ *Corresponding author: zknagy@purdue.edu
}


1 The estimated kinetic parameters were used to build a population balance model for the

2 calculation of the optimal temperature profile needed, during a batch cooling crystallization

3 process, for the (i) elimination of the metastable form crystals nucleated in situ or erroneously

4 seeded and the (ii) maximisation of the size of the crystals of the stable polymorph obtained at

5 the end of the batch process.

6

7 Keywords: polymorphic control, population balance equations, batch crystallization 8 optimization.

\section{Introduction}

Polymorphs of the same compound can have different physical characteristics such as solubility, stability, melting point and, most importantly, bioavailability. For this reason both discovering new polymorphs and designing new control strategies to tailor the polymorphic purity of the final product crystallized in industrial processes is very important. The choice of solvent, supersaturation conditions, temperature, $\mathrm{pH}$ and the use of additives can determine the polymorphic outcome of a cooling crystallization, while PAT tools can be used to check the purity of the final product and control its growth. ATR-FTIR, ATR-UV/Vis, in situ Raman and FBRM have been frequently used to control the growth of both stable and metastable polymorphs through different control approaches. Recently a feedback control technique, the active polymorphic feedback control (APFC), was developed to select and grow the desired polymorphic form of the crystallized compound (Simone et al. 2014). In this strategy both Raman and ATR-UV/Vis spectroscopy are used: the Raman probe can detect the nucleation or seeding of a polymorphic mixture and it eliminates the metastable form by triggering a controlled dissolution cycle. 


\section{Control approach}

Seeding the desired form between the solubility curve and the metastable limit line in order to avoid the nucleation of the other form and keep cooling until the supersaturation is consumed

\section{Reference}

(Threlfall 2000; Beckmann

Finding the correct amount of seed above which secondary nucleation of (Doki et al. 2003)

the metastable form is suppressed and solution-mediated transformation is avoided in a cooling crystallization

Seeding during a cooling crystallization and using focused beam

(Doki et al. 2004)

reflectance measurement (FBRM) in combination with ATR-FTIR to

check the total counts and the supersaturation in order to reach the desired

size of the crystals and eliminate the fines via dissolution

Temperature control and concentration control for the conversion of the

(Hermanto et al. 2007; Kee

metastable form of a polymorph to its stable form (simulation and

et al. 2009; Kee, et al. 2009;

experimental work)

Hermanto et al. 2009)

Seeding and growth of the metastable form during a cooling

(Kee et al. 2009; Chew et al.

crystallization performing supersaturation control

Combination of anti-solvent and cooling crystallization was performed to

(Minamisono and Takiyama

obtain the desired form of indomethacin in acetone

2013)

Feedback control of the reactive crystallization of L-glutamic acid in a

(Qu et al. 2009; Alatalo et al.

semi-batch precipitation was conducted using MID-IR or Raman, ATR-

FTIR and a $\mathrm{pH}-\mathrm{meter}$

Control of Polymorphism in Continuous Crystallization via Mixed

(Lai et al. 2015)

Suspension Mixed Product Removal Systems Cascade Design: estimation

of the optimal operating conditions to crystallize one specific polymorph

3 
1 ATR-UV/Vis is instead used to control the crystallization under conditions and allow only the

2 growth of the stable form using supersaturation control. Other control approaches proposed in

3 the literature either use the Raman system only to detect the formation of the unwanted

4 polymorph as a trigger to restart the crystallization with a different cooling rate, or use only

5 supersaturation control in conjunction with the suitable seeding procedure to drive the system

6 in the phase diagram to obtain the desired polymorphic form. A summary of recent research

7 works on polymorphic control is shown in Table 1.

8 The APFC strategy is a model-free approach, which was evaluated for the cooling

9 crystallization of ortho-aminobenzoic acid, and led to pure polymorphic forms in the case of

10 unseeded crystallization processes where nucleation of polymorph mixtures occurred, or for

11 seeded crystallization with contaminated seed crystals containing an unwanted polymorph

12 impurity (Simone et al. 2014). During the experiments performed, a partial dissolution of the

13 desired form together with the elimination of the undesired form was observed. However, it is

14 not clear whether such partial dissolution favours the attainment of larger crystals of the stable

15 form at the end of the batch or not. A model based approach can help understanding if the

16 initial dissolution cycle improve or worsen the final size distribution of the crystals of the

17 stable form and how the temperature profile could be optimized in order to maximize such

18 distribution. The aim of this work is to develop a model-based active polymorphic control by

19 determining the kinetic parameters of the growth and polymorphic transformation of ortho-

20 aminobenzoic acid through properly designed experiments, and then by simulating and

21 optimizing the batch crystallization process in order to control both size and polymorphic 22 purity of the final crystals. 
1 Parameter estimation and modelling of polymorphic transformation has rarely been performed

2 because of the complexity of the phenomenon, which involves two steps: dissolution of the

3 metastable form and nucleation and growth of the stable one (Cardew and Davey, 1985).

4 A first example of population balance applied to a polymorphic transformation was the study 5 on the conversion of citric acid from the anhydrate to its monohydrate form (Fevotte et al.

6 2007). Seeded isothermal experiments were conducted to estimate the kinetic parameters for 7 the growth and nucleation of the monohydrate form as well as for the dissolution of the 8 anhydrate form. Power-law relationships were used to express dissolution and growth as a 9 function of supersaturation, while secondary nucleation was expressed as a function of 10 supersaturation as well as of the concentration of crystals of the stable form present in 11 suspension. Raman and image analysis were used to measure solute concentration, crystal size distribution and polymorphic ratio; a finite elements method was used to solve the population balance equation, PBE (using the software FEMLAB). Many different solution techniques were used to solve the PBE for the polymorphic transformation of L-glutamic acid: moving pivot technique (Cornel et al. 2009), finite volume method in gPROMS (Ono et al., 2004) and the method of moments (Hermanto et al. 2007; Hermanto et al. 2009; Hermanto et al. 2011; Sheikholeslamzadeh and Rohani 2013). Despite working with the same system the authors of the mentioned studies used different types of equations to express the kinetics of the phenomena involved in the polymorphic transformation of L-glutamic acid. All the authors found a good agreement between simulated and experimental data, even when semi-empirical, 21 simplified functions were used.

22 Ono et al. included in the model only dissolution of the metastable form (Sherwood correlation), size-dependent growth and secondary nucleation (semi-empirical function of supersaturation and mass of crystals of the stable form in slurry) of the stable form. More 
1 phenomena were included in the models described by Hermanto et al. (2011), Cornel et al. 2 (2009) and Sheikoleslamzadeh and Rohani (2013): primary nucleation and dissolution of the 3 metastable form, secondary nucleation and growth of the stable form. Besides, less empirical 4 correlations were used in such studies compared to the model described by Ono et al. (2004). 5 In fact, the growth kinetics of the stable and metastable polymorphs of L-glutamic acid were 6 found to be integration controlled and of the birth-and-spread type, with the exception of the 7 studies performed by Hermanto and co-workers, where a power-law function was used to express the growth rate of the metastable form. A Sherwood correlation was used to estimate

9 the dissolution of the metastable form in all the referenced works. The functions used to 10 express the nucleation rates for both the stable and metastable forms of L-glutamic acid were 11 different in the mentioned studies: Cornel at al. (2009) and Sheikoleslamzadeh and Rohani (2013) used primary nucleation exponential functions to describe the primary nucleation of the metastable form, while Hermanto et al. (2011) employed a simpler equation as a function of supersaturation and the third moment calculated for the metastable form. The kinetic of secondary nucleation of the stable form of L-glutamic acid was expressed with a semiempirical function only of the mass of metastable crystals by Cornel et al. (2009) and of the mass of both the stable and metastable crystals by Hermanto et al. (2011) Sheikoleslamzadeh and Rohani (2013) instead employed a two-terms expression to estimate both the heterogeneous (exponential nucleation function) and surface secondary nucleation (as a

20 function of the second moment of the metastable crystals) of stable L-glutamic acid.

21 The solution-mediated transformation of DL-methionine polymorphs was modelled by 22 Wantha and Flood (2013) using the method of moments to solve the PBEs. In this work semiempirical functions of the supersaturation were used to express the growth kinetics of both 
1 forms and the dissolution kinetics of the metastable polymorph; a primary nucleation

2 exponential function was used to estimate nucleation of the stable polymorph.

3 Schöll et al. (2006) solved the PBEs using the commercial software PARCIVAL for the 4 parameter estimation of the kinetics of transformation of L-glutamic acid (Schöll et al. 2006).

5 The model used included the kinetics of heterogeneous nucleation of the metastable form 6 (exponential primary nucleation type function), size-independent growth rates of both the 7 stable and metastable forms (integration controlled and birth and spread type of functions), 8 dissolution of the metastable form (Sherwood correlation) and heterogeneous and surface 9 nucleation of the stable form. A similar model was used to describe the polymorphic 10 transformation of Buspirone hydrochloride from the metastable form II to stable form I 11 (Trifkovic et al. 2012). Such model was solved using the methods of moments.

12 More recently, the methods of characteristics was used to describe the behaviour of the $\alpha$ and

$13 \beta$ forms of para-aminobenzoic acid in a two stages MSMPR reactor (Lai et al. 2015). The 14 authors included in the model the growth of both stable and metastable forms (sizeindependent and surface integration controlled) and their secondary nucleation (semiempirical equation as a function of the mass of crystals in suspension). As explained in the previous paragraph, population balance models in the literature can include or not primary nucleation of both the stable and the metastable form but all of them

19 include secondary nucleation of the stable form, expressed with semi-empirical functions, 20 primary heterogeneous nucleation exponentials or with two-terms functions including both 21 heterogeneous primary nucleation and surface secondary nucleation. In fact, secondary 22 nucleation of the stable form and dissolution of the metastable polymorph are the key 23 mechanisms happening during a polymorphic transformation (Cardew and Davey, 1985). 
1 Only one theoretical study considered the presence of secondary nucleation of the metastable

2 form and analysed its effect on the transformation time and the concentration profile (Kobari

3 et al. 2014). However, the presence of secondary nucleation of the metastable form can be

4 neglected if, during the crystallization process, the solute concentration is very close, or below

5 the solubility of the metastable form. Thus, the supersaturation is too low to allow secondary

6 nucleation.

7 The parameters necessary to define and model the active polymorphic control of ortho-

8 aminobenzoic acid are: (i) dissolution kinetics for both forms, (ii) growth kinetics for both

9 forms, (iii) secondary nucleation of the stable form (during transformation), and (iv) primary

10 nucleation of the stable form (during transformation and after seeding far from the solubility

11 curve). The estimated parameters will be then validated and applied to an optimization problem in order to design batch cooling crystallization processes that allow the growth of

13 large crystals of the stable polymorph even in case of erroneous seeding or in situ nucleation 14 of a mixture of the stable and metastable forms. In conclusion, the model-based active 15 polymorphic control (mbAPC) proposed in this work represents a useful approach for the 16 correct design of batch crystallization processes for polymorphic systems.

\section{Materials and Methods}

19 The model compound used for the experiments is ortho-aminobenzoic acid (OABA), which 20 has three known different polymorphic forms (Jiang et al. 2010b; Jiang et al. 2010a; Jiang et 21 al. 2008). The transformation studied in this work is the one from the metastable form II to 22 the stable form I in a solution of $90 \%$ water and $10 \%$ IPA, below $50^{\circ} \mathrm{C}$ (see Figure $1 \mathrm{a}$ and $\mathrm{b}$ ). 23 OABA ( $>98 \%$ Form I, Sigma-Aldrich), isopropyl alcohol (99.97\%, Fisher Scientific) and 24 ultrapure water obtained via a Millipore ultra-pure water system, were used. Experiments 
1 were performed in a $400 \mathrm{ml}$ jacketed vessel; a PT-100 temperature probe connected to a

2 Huber Ministat 230 thermoregulator was used to control the temperature. A RXN1 Raman 3 analyser with immersion probe and $785 \mathrm{~nm}$ laser (Kaiser with iC Raman 4.1 software) was

4 used to capture detect different polymorphs in suspension, while a MSC621 Carl Zeiss 5 UV/Vis (in-house LabView software) with Hellma ATR (type 661.822-UV) probe was used 6 to determine the solute concentration. A Malvern Mastersizer 2000 was used to determine the 7 crystal size distribution at the beginning and during the experiments.
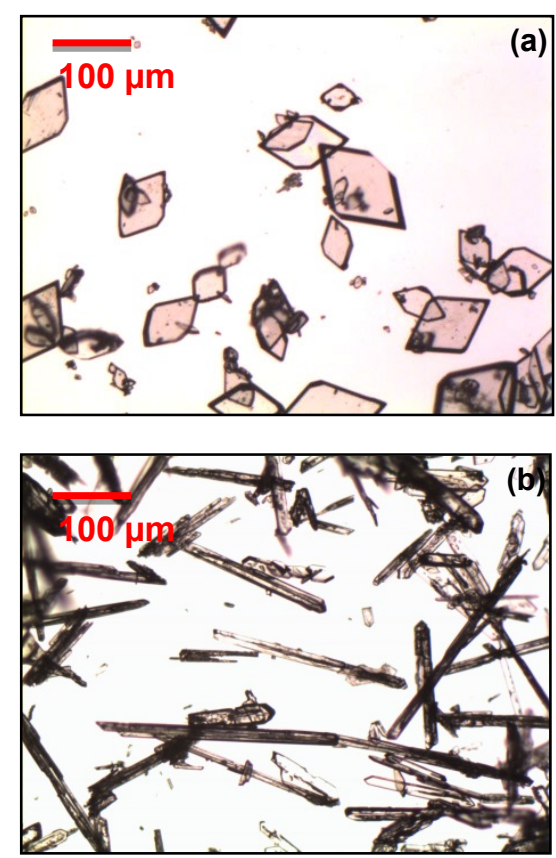

Figure 1: Micrographs of OABA crystals: (a) prismatic form I, and (b) needle-like form II.

11 The mean and the standard deviation of the crystal size distributions measured using the

12 Mastersizer, were used to calculate a Gaussian curve that approximate the experimental data.

13 This approximation was necessary to avoid the overestimation of fine particles in the 14 measured samples, due to the non-spherical shape of the OABA crystals of both polymorphic

15 forms. In fact, the volume and number distributions of needles and flat crystals measured by 16 laser diffraction can show a large number of fine crystals (or even a bimodal shape) simply 
1 because of the orientation of elongated particles on their shortest side during the measurement

2 (Su et al. 2017).

3 A previously developed calibration model (Simone et al. 2014) was used to determine solute

4 concentration from ATR-UV/Vis while specific Raman peaks for form I and II were tracked

5 during the experiments to estimate the rate of transformation and check the composition of the

6 slurry during the experiments performed with the metastable polymorph. Furthermore, the

7 initial seeds were analysed with a Raman microscope (DXR Raman, Thermofisher) in order

8 to check their purity.

9 The solubility curves for both form I and II between 10 and $40{ }^{\circ} \mathrm{C}$ were estimated using an the

10 ATR-UV/Vis probe (interpolating data from a slow heating profile). Despite the system being

11 enantiontropic (Jiang et al. 2010b; Jiang et al. 2010a; Jiang et al. 2008), in the used

12 temperature interval the two OABA polymorphs can be considered monotropically related.

13 The formulas used for the solubility (Simone et al. 2014) are:

$14 S_{I}=1.267 \cdot 10^{-5} T^{2}-2.283 \cdot 10^{-4} T+4.105 \cdot 10^{-3}$

$15 S_{I I}=1.299 \cdot 10^{-5} T^{2}-2.082 \cdot 10^{-4} T+4.808 \cdot 10^{-3}$

16 with the temperature $T$ expressed in ${ }^{0} \mathrm{C}$ and the solubility $S_{I}$ and $S_{I I}$ calculated in $\mathrm{g} / \mathrm{g}$ solvent.

17 The solubility of form II and form I have been interpolated with polynomial functions and not

18 with a Van't Hoff type equation to keep consistency with our previous experimental APFC

19 study (Simone et al. 2014). In such paper polynomials were used as this is the only type of

20 equation that can be currently input in the in-house software (CryPRINS) to perform

21 supersaturation control during batch crystallization experiments. 


\section{$1 \quad 2.1$ Population balance model and solution}

2 For the description of a particle population, let us introduce the monovariate number density

3 function $f(L, t) d L$, which expresses the number of crystals within the $L, L+d L$ crystal size

4 domain ( $L$ expressed in $\mu \mathrm{m})$ in unit volume of suspension in the $t$ time moment (expressed in

5 seconds). Then, population balance equations can be used to predict and simulate

6 polymorphic transformations considering one equation for each polymorph. Three main

7 mechanisms must be considered during a transformation: nucleation and growth of the more

8 stable form and the dissolution of the less stable polymorph. In the mbAPC also dissolution of

9 form I must be considered and estimated. Indicating with the index $I I$ the parameters of the

10 metastable form of OABA, and with $I$ the ones of the stable one, the PBE for the studied

11 system, using the simplified $f(L, t) \rightarrow f$ notations, are:

$12 \frac{\partial f_{I I}}{\partial t}=\frac{\partial\left(D_{I I} f_{I I}\right)}{\partial L}$

13 for dissolution of form II,

$14 \quad \frac{\partial f_{I I}}{\partial t}+\frac{\partial\left(G_{I I} f_{I I}\right)}{\partial L}=0$

15 for growth of form II,

$16 \frac{\partial f_{I}}{\partial t}=\frac{\partial\left(D_{I} f_{I}\right)}{\partial L}$

17 for dissolution of form I, and

$18 \quad \frac{\partial f_{I}}{\partial t}+\frac{\partial\left(G_{I} f_{I}\right)}{\partial L}=B_{I} \delta\left(L-L_{0}\right)$ 
1 for growth and nucleation of form I: where $f_{I I}$ and $f_{I}$ are the average number density

2 functions of the metastable and stable form of OABA and $\delta\left(L-L_{0}\right)$ is the Dirac delta

3 function $\left(\delta=\infty\right.$ if $L=L_{0}=0$ and $\delta=0$ if $L \neq L_{0}$ with $\left.\int_{-\infty}^{+\infty} \delta(x) d x=1\right)$.

4 In order to close the system of equations that characterize the presented model the liquid 5 phase mass balance is required (temperature is the controlled variable, therefore, the energy 6 balance is not necessary):

$$
\frac{d \mathrm{c}}{d t}=-3 k_{v} \rho_{C}\left[\int_{0}^{\infty} G_{I} L^{2} f_{I} d L+\int_{0}^{\infty} G_{I I} L^{2} f_{I I} d L\right]
$$

7 Where $k_{v}$ is the volume shape factor and $\rho_{C}$ stands for the crystal density. The mass balance 8 Eq.(7) refers to the case when both populations are growing and it considers 0 nucleon size.

9 The equation remains valid for dissolution by applying simply $D_{I} / D_{I I}$ dissolution rates.

$10 D_{I}$ and $D_{I I}$ are the dissolution rates of the two forms and $G_{I}$ and $G_{I I}$ the growth rates of form I 11 and II defined as:

$$
D_{I}\left[\frac{\mu m}{s}\right]=k_{d I}\left(1-S_{I}\right)^{d_{I}} \exp \left(\frac{E d_{I}}{R T}\right)
$$

$13 D_{I I}\left[\frac{\mu m}{s}\right]=k_{d I I}\left(1-S_{I I}\right)^{d_{I I}} \exp \left(\frac{E_{I I}}{R T}\right)\left(1+L_{I I}\right)$

$14 \quad G_{I}\left[\frac{\mu m}{s}\right]=k_{g I}\left(S_{I}-1\right)^{g_{I}} \exp \left(\frac{E_{g I}}{R T}\right)$

$15 G_{I I}\left[\frac{\mu m}{s}\right]=k_{g I I}\left(S_{I I}-1\right)^{g_{I I}} \exp \left(\frac{E_{g I I}}{R T}\right)\left(1+L_{I I}\right)$

16 with the supersaturation defined as $S_{I, I I}=\frac{C}{C_{s a t l, I I}}$. 
1 Two types of nucleation of the stable form were estimated: (i) primary nucleation after

2 seeding of a mixture of polymorphs if $c_{I}>c_{\text {satII }}$ (ii) secondary nucleation during 3 polymorphic transformation (if $c_{I}>c_{\text {satI }}$ ). The different types of nucleation can be described 4 by the equation:

$5 \quad B_{I}\left[\frac{\#}{m^{3} \sec }\right]=k_{b}\left[\frac{b}{\left(\log S_{I}\right)^{2}}\right] \exp \left(-\frac{E_{b}}{R T}\right)+k_{S}\left(1-S_{I}\right)^{S} \exp \left(-\frac{E_{S}}{R T}\right)$

6 A high resolution finite volume method (HR-FVM) was used to solve the model-equations

7 (Gunawan et al. 2004). The basic idea of HR-FVM is the discretization of the continuous

8 population density function; denoting with $h$ the size and $k$ the time interval, $f_{l}^{m}$ is the

9 approximate (discrete) population density function defined as:

$f_{l}^{m} \approx \frac{1}{h} \int_{(l-1) h}^{l h} f(L, m k) d L$

10 where $m$ and $l$ are integers such that $m \geq 0$ and $N \geq l \geq 1$ and $N$ stands for the mesh size (i.e.

11 the number of discretization points). Then, the population balance Eq. (6) reduces to a system

12 of algebraic equations:

$$
\begin{aligned}
f_{l}^{m+1}=f_{l}^{m} & -\frac{k}{h}\left(G_{l} f_{l}^{m}-G_{l-1} f_{l-1}^{m}\right) \\
& -\left[\frac{k G_{l}}{2 h}\left(1-\frac{k G_{l}}{h}\right)\left(f_{l+1}^{m}-f_{l}^{m}\right) \phi_{l}\right. \\
& \left.-\frac{k G_{l-1}}{2 h}\left(1-\frac{k G_{l-1}}{h}\right)\left(f_{l}^{m}-f_{l-1}^{m}\right) \phi_{l-1}\right] \\
& +\epsilon_{b} \frac{k}{h} B
\end{aligned}
$$

13 In Eq. (14) $\epsilon_{b}$ is a binary existence variable with values $\{0,1\}$ which controls the existence of 14 nucleation. In this PBE formulation, $\epsilon_{b}=1$ if $l=1$ (nucleon size) and is 0 otherwise. It is 
1 worth noticing that the same Eq. (14) equation is used for growth and dissolution stages,

2 treating the dissolution as negative growth and keeping in mind that the nucleation rate is 0 if

3 the solution is undersaturated. $\phi_{l}=f\left(\theta_{l}\right)$ is the flux limiter function and $\theta_{l}$ is the ratio of

4 consecutive gradients:

$\theta_{l}=\frac{f_{l}^{m}-f_{l-1}^{m}}{f_{l+1}^{m}-f_{l}^{m}}$

5 The Van Leer flux limiter of Eq. (16) has been successfully applied in the solution of

6 population balance equations thus is adopted in this study too (Gunawan et al. 2004).

$\phi\left(\theta_{l}\right)=\frac{\left|\theta_{l}\right|+\theta_{l}}{1+\left|\theta_{l}\right|}$

7 Note that the numerical apparatus Eqs. (13) - (16) applies for both populations: $f_{l}^{m} \rightarrow f_{I, l}^{m}$

8 (with $G_{I, l}, D_{I, l}$ and $B_{I}$ ) and $f_{l}^{m} \rightarrow f_{I I, l}^{m}$ (with $G_{I I, l}, D_{I I, l}$ and $B_{I I}=0$ ). The resulted algebraic

9 equation systems are solved simultaneously.

10 The time step is recalculated in all iterations to satisfy the Courant-Friedrichs-Lewy (CFL)

11 criterion and the numerical system is stable if CFL $\leq 1$.

$C F L=\frac{k}{h} \max \left\{G_{I, l}, G_{I I, l}, D_{I, l}, D_{I I, l}\right\}$

12 Practically the $C F L$ is fixed and $k$ is expressed from Eq. (17). Finally, the solute mass balance

13 takes the form:

$c^{m+1}=c^{m}-3 k_{v} \rho_{C} h^{2} \sum_{l=1}^{N} L^{2}\left[f_{I, l}^{m} G_{I, l}+f_{I I, l}^{m} G_{I I, l}\right]$

14 Similarly to the Eq,(14), the mass balance Eq.(18) is applicable for dissolution as well,

15 involving the dissolution rate for undersaturated conditions. An extended version of the 16 CrySiV function (Szilagyi and Nagy, 2016) was used to efficiently solve the equation system 
1 and a combination of Evolution Strategy with Covariance Matrix Adaptation (ES-CMA)

2 global optimization algorithm (Hansen et al. 2003) and Matlab's nlinfit function (Levenberg-

3 Marquardt algorithm) was employed to estimate the parameters and the confidence intervals.

\section{$4 \quad 2.2$ Systematic experimental design for the model identification}

5 Experiments were planned carefully in order to simplify the estimation of the kinetic

6 parameters: the different phenomena were isolated as shown in Figure 2. Growth and

7 dissolution for both forms were estimated through seeded saturation or desupersaturation

8 experiments. The secondary nucleation of the stable form was estimated through isothermal

9 transformation experiments and using the dissolution and growth kinetics already estimated.

10 Finally secondary nucleation of form I after seeding was evaluated through desupersaturation

11 experiments with low seeds loading at high supersaturation.

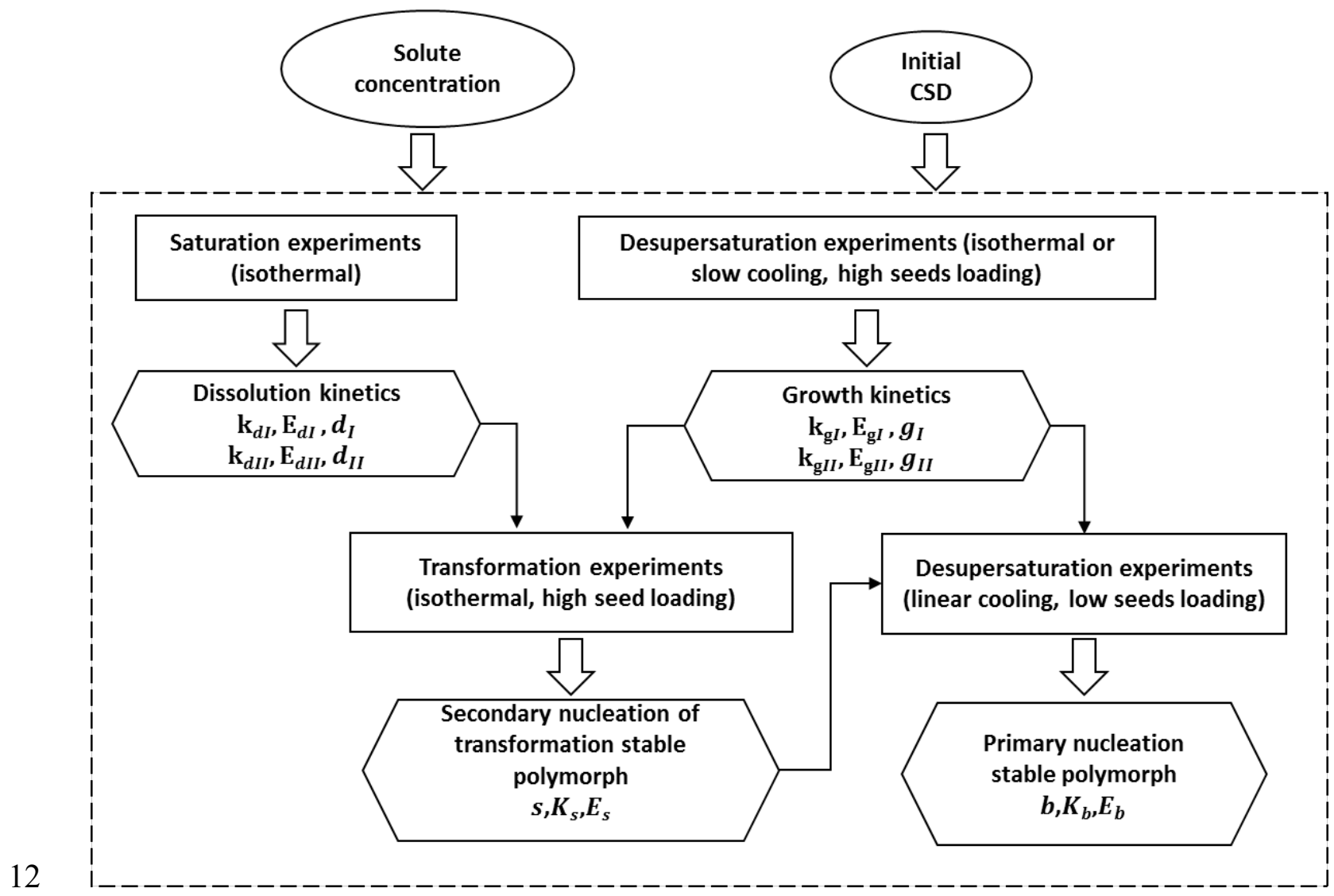


Figure 2: Schematic of the experimental design used for the parameters estimation. Growth and dissolution for both stable form was estimated through isothermal transformation experiments and using the dissolution and growth kinetics already estimated. Finally secondary nucleation of form I after seeding was evaluated through desupersaturation experiments with low seeds loading at high supersaturation.

This approach has two main advantages: (i) a correlation between the estimated parameters is avoided because only one phenomenon occurs in each set of experiments; (ii) only concentration data and the initial crystal size distribution (CSD) are needed for the estimation, sampling is not necessary to estimate the CSD during the crystallization process (Besenhard et al. 2015). Therefore, in this work the concentration profile is the only measured output used for the fitting procedure.

The present systematic approach allows the determination of the necessary kinetics parameters using only limited CSD data, which can often be unreliable. In fact, such data cannot be easily obtained online by standard process analytical technologies (e.g. FBRM) and is often estimated via off-line techniques such as optical or scanning electron microscopy or laser diffraction. The need of sampling and the off-line nature of the traditional CSD measurement techniques lower the accuracy and reliability of the collected data. A detailed list of the experiments performed and their conditions is shown in Table 2. Some of the experiments reported in Table 2 could be conducted consecutively in the same solution: growth of the metastable form can be estimated by a seeded experiment that can then be used to estimate secondary nucleation of the stable form by just letting the metastable form transform. In these cases, sampling at the beginning of the transformation is necessary to estimate the initial crystal size distribution to use in the parameter estimation. In particular, the kinetic parameters of growth of form II $\left(k_{g I I}, E_{g I I}\right.$ and $\left.g_{I I}\right)$ and secondary nucleation of form I $\left(s, k_{\mathrm{s}}\right.$ and $\left.E_{s}\right)$ were estimated from the same isothermal experiments, number 11 to 14 , 
1 each one conducted at a different temperature. All data points before the start of the

2 nucleation of the stable form were used to estimate the growth of the metastable form II,

3 while data collected after the appearance of the stable form were used for the estimation of the

4 kinetics of secondary nucleation of such polymorph.

5

Table 2: Description of the conditions used in the different experiments to determine the kinetics parameters of 7

OABA.

\begin{tabular}{|c|c|c|}
\hline $\begin{array}{l}\text { Parameter } \\
\text { estimated }\end{array}$ & Experimental conditions & $\begin{array}{l}\text { Experiment } \\
\text { number }\end{array}$ \\
\hline$k_{d I}, E_{d I}$ and $d_{I}$ & $\begin{array}{l}\text { Four isothermal experiments }\left(10,15,25 \text { and } 35^{\circ} \mathrm{C}\right) \text {. Seeds were } \\
\text { added to the solvent in the amount necessary to have a saturated } \\
\text { solution after the complete dissolution }\end{array}$ & $1-4$ \\
\hline$k_{d I I}, E_{d I I}$ and $d_{I I}$ & $\begin{array}{l}\text { Four isothermal experiments }\left(10,15,25 \text { and } 35^{\circ} \mathrm{C}\right) \text {. Seeds were } \\
\text { added to the solvent in the amount necessary to have a saturated } \\
\text { solution. Raman spectroscopy was used to check the absence of } \\
\text { polymorphic transformation during dissolution }\end{array}$ & $5-8$ \\
\hline$k_{g I}, E_{g I}$ and $g_{I}$ & $\begin{array}{l}\text { Seeds }(10 \% \text { of the total solute) were added to a saturated solution } \\
\text { at } 40^{\circ} \mathrm{C} \text {. A slow linear cooling was then applied to avoid } \\
\text { nucleation. Two experiments at different cooling rates were } \\
\text { performed }\left(-0.1 \text { and }-0.05^{\circ} \mathrm{C} / \mathrm{min}\right)\end{array}$ & $9-10$ \\
\hline$k_{g I I}, E_{g I I}$ and $g_{I I}$ & $\begin{array}{l}\text { Four isothermal experiments }\left(10,15,25 \text { and } 35^{\circ} \mathrm{C}\right) \text {. Seeds of the } \\
\text { metastable form }(10 \% \text { of the total solute }) \text { were added to } \\
\text { supersaturated solutions }\left(5^{\circ} \mathrm{C} \text { of supersaturation) }\right.\end{array}$ & $\begin{array}{l}\text { 11-14 (Data points } \\
\text { until the nucleation } \\
\text { of the stable form } \\
\text { started) }\end{array}$ \\
\hline$s, k_{\mathrm{s}}$ and $E_{s}$ & $\begin{array}{l}\text { Isothermal seeded polymorphic transformation experiments at four } \\
\text { different temperatures }\left(10,15,25 \text { and } 35^{\circ} \mathrm{C}\right)\end{array}$ & $\begin{array}{l}\text { 11-14 (Data points } \\
\text { after the nucleation } \\
\text { of the stable form }\end{array}$ \\
\hline
\end{tabular}


started)

$b, k_{b}$ and $E_{b} \quad$ Seeding of a mixture of polymorphs at saturated condition for form $15-17$

II (about $40{ }^{\circ} \mathrm{C}$ ) and cooling at $-1{ }^{\circ} \mathrm{C} / \mathrm{min}$ (three experiments,

amount of seeds of $10 \%$ of the total solute)

2 The results of one of the combined experiments are shown in Figure 3. Growth of metastable

3 form and secondary nucleation of the stable form at $10{ }^{\circ} \mathrm{C}$ are measured. The first $4000 \mathrm{~s}$ of

4 the experiment were used, together with the other three isothermal growth experiments, to

5 estimate growth of form II while the remaining time was used to estimate secondary

6 nucleation of form I. Another important piece of information shown in Figure 3 is that the

7 system can be considered neither growth nor dissolution controlled as in the case of 8 previously studied compounds.

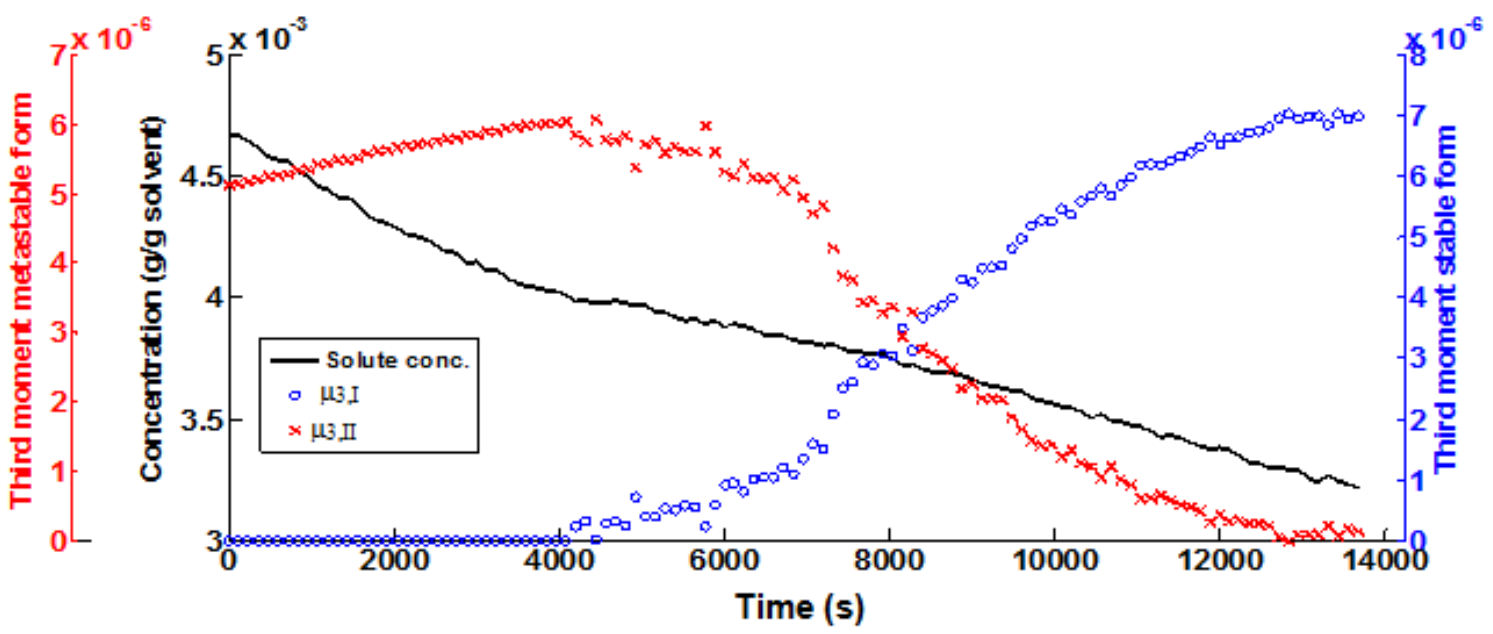




\section{3. Results and Discussion}

\subsection{Parameters estimation and validation}

3 The kinetic parameters estimated from all the experiments are shown in Table 3 while Figures

44 to 7 show the simulated and experimental data for dissolution and growth of form I and II at

5 different conditions, as well as the two types of nucleation. In order to validate the parameters

6 estimated a leave-one-out cross-validation was performed using all the available experiments.

7

Table 3: Kinetic parameters estimated from the performed experiments.

\begin{tabular}{|c|c|c|c|}
\hline Parameter & Value & $\begin{array}{l}\text { Upper limit of the } 95 \% \\
\text { interval of confidence }\end{array}$ & $\begin{array}{l}\text { Lower limit of the } 95 \% \\
\text { interval of confidence }\end{array}$ \\
\hline$k_{d I}\left[\frac{\mu m}{s}\right]$ & $-3.45 \cdot 10^{8}$ & $-1.38 \cdot 10^{8}$ & $-5.6 \cdot 10^{8}$ \\
\hline$E_{d I}\left[\frac{\mathrm{kJ}}{\mathrm{mol}}\right]$ & 48091 & 49587 & 46595 \\
\hline$d_{I}[-]$ & 0.65 & 0.69 & 0.61 \\
\hline$k_{d I I}\left[\frac{\mu m}{s}\right]$ & -204 & -101 & -307 \\
\hline$E_{d I I}\left[\frac{k J}{m o l}\right]$ & 24276 & 25545 & 23001 \\
\hline$d_{I I}[-]$ & 0.87 & 0.91 & 0.83 \\
\hline$k_{g I}\left[\frac{k J}{m o l}\right]$ & $6.20 \cdot 10^{13}$ & $1.39 \cdot 10^{14}$ & $8.84 \cdot 10^{12}$ \\
\hline$E_{g I}\left[\frac{k J}{m o l}\right]$ & 90628 & 93378 & 87877 \\
\hline$g_{I}[-]$ & 0.82 & 0.88 & 0.75 \\
\hline$k_{\mathrm{g} I I}\left[\frac{k J}{m o l}\right]$ & 0.00232 & 0.00449 & 0.00014 \\
\hline$E_{g I I}\left[\frac{k J}{m o l}\right]$ & 9466 & 11388 & 7445 \\
\hline$g_{I I}[-]$ & 0.41 & 0.47 & 0.36 \\
\hline$k_{s}\left[\frac{\#}{m^{3} s e c}\right]$ & $7.92 \cdot 10^{4}$ & $4.84 \cdot 10^{6}$ & $1.34 \cdot 10^{2}$ \\
\hline
\end{tabular}




\begin{tabular}{llll}
\hline$E_{S}\left[\frac{k J}{m o l}\right]$ & -42323 & -24254 & -60300 \\
\hline$s[-]$ & 3.95 & 4.86 & 3.04 \\
\hline$k_{b}\left[\frac{\#}{m^{3} s e c}\right]$ & $6.02 \cdot 10^{42}$ & $1.85 \cdot 10^{70}$ & $2.69 \cdot 10^{14}$ \\
\hline$E_{b}\left[\frac{k J}{m o l}\right]$ & 179480 & 348390 & 164390 \\
\hline$b[-]$ & $0.1^{*}$ & 0.0129 & -0.054 \\
\hline$*$ Lower bound of searching domain
\end{tabular}

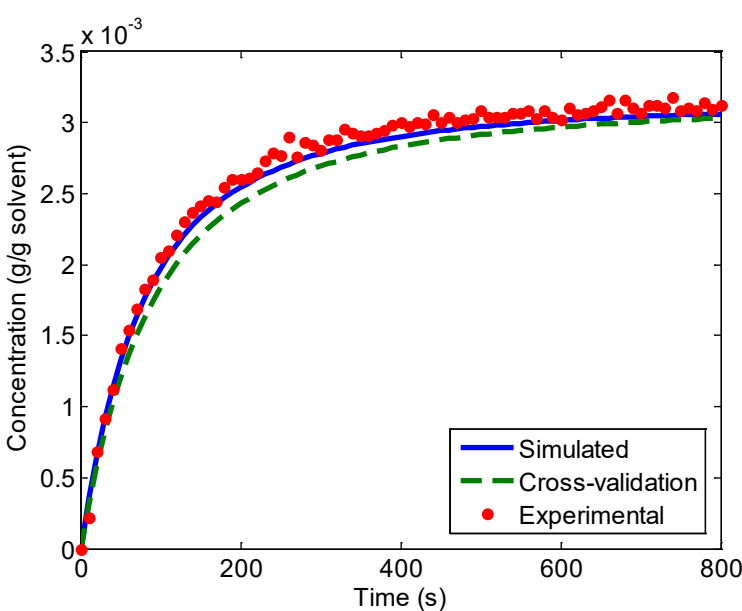

(a)

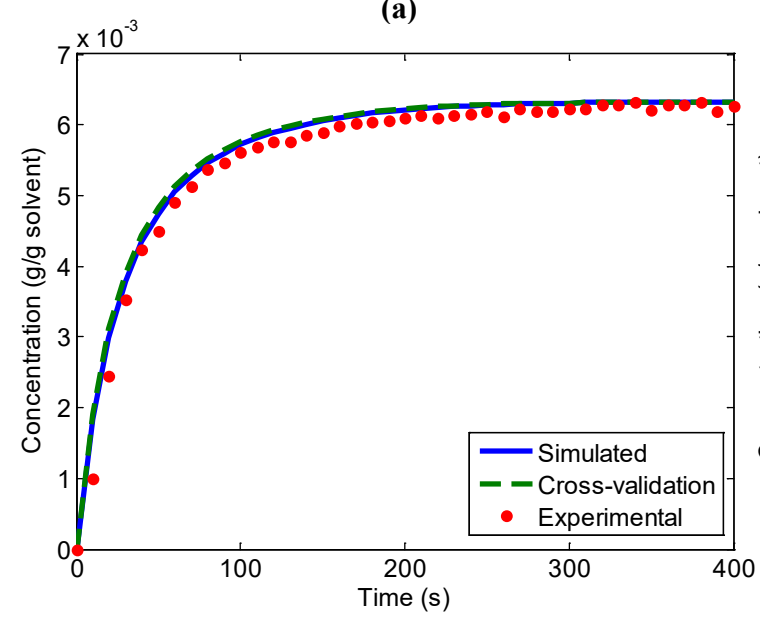

(c)

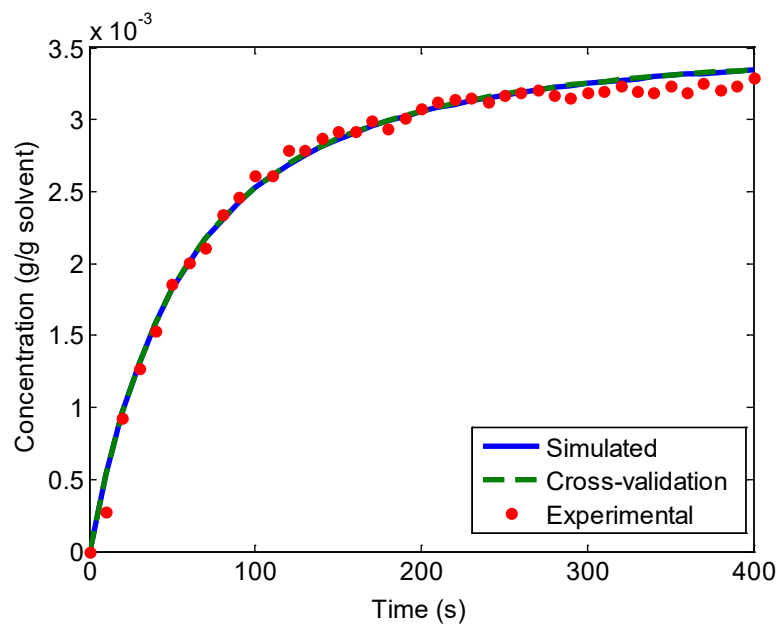

(b)

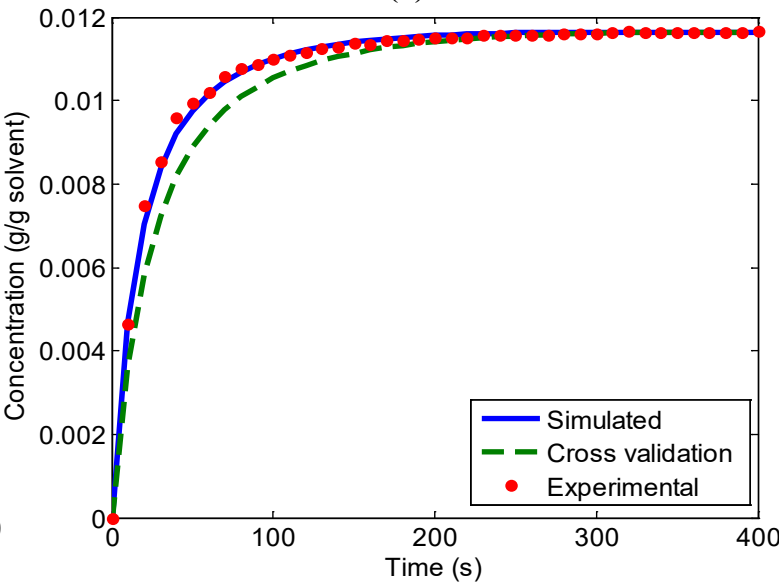

(d)

3 Figure 4: Dissolution experiments for form I: (a) Experimental, fitted and cross-validation concentration profile for the dissolution of form $\mathrm{I}$ at $10{ }^{\circ} \mathrm{C}$

(b) Experimental, fitted and cross-validation concentration profile for the dissolution of form I at $15{ }^{\circ} \mathrm{C}$ (c) Experimental, fitted and cross-validation concentration profile for the dissolution of form I at $25^{\circ} \mathrm{C}$ (d) Experimental, fitted and cross-validation concentration profile for the dissolution of form I at 35 ${ }^{\circ} \mathrm{C}$. 
2 Figure 4 shows, for each dissolution experiment performed with form I, the experimental data

3 for concentration together with the best fit (obtained using all the available experiments) and

4 the calculated concentration for the cross validation (calculated using the parameters obtained

5 by leaving that experiment out of the estimation).

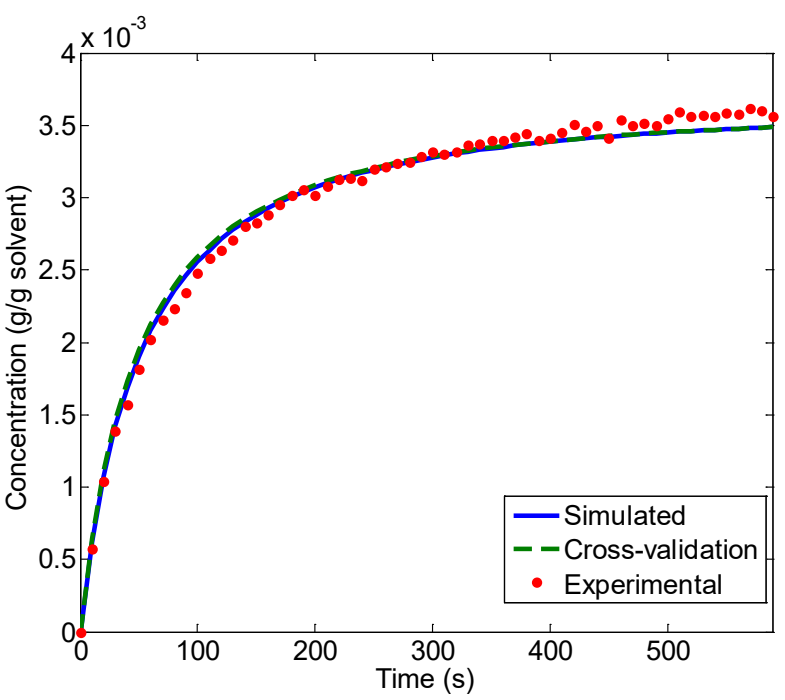

(a)

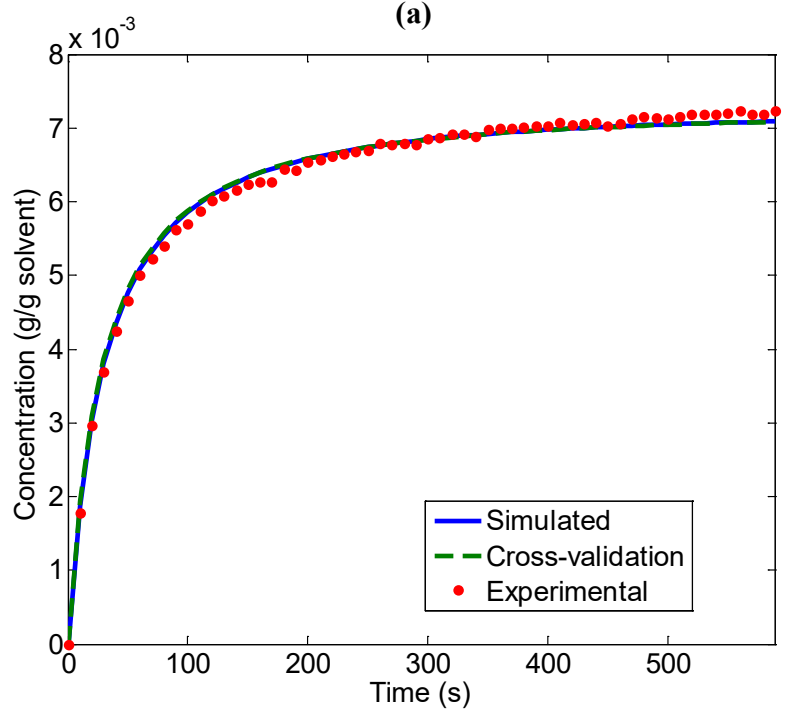

(c)

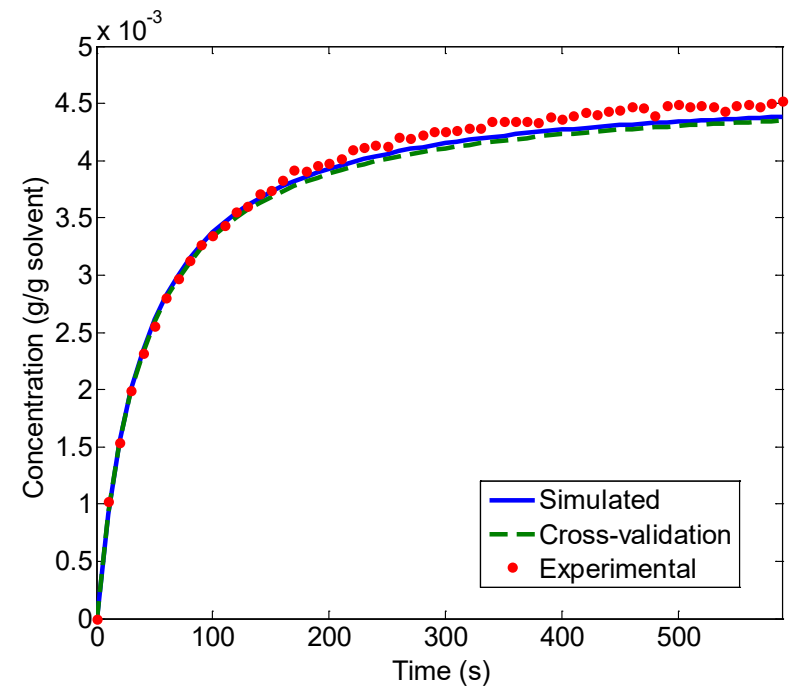

(b)

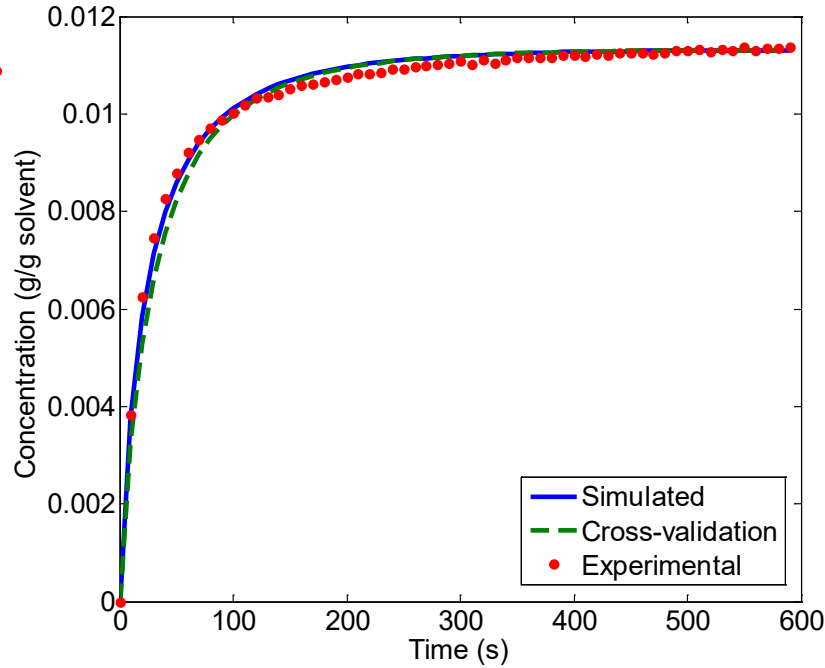

(d)

Figure 5: Dissolution experiments for form II: (a) Experimental, fitted and cross-validation concentration profile for the dissolution of form $\mathrm{II}$ at $10{ }^{\circ} \mathrm{C}$

(b) Experimental, fitted and cross-validation concentration profile for the

dissolution of form II at $15^{\circ} \mathrm{C}$ (c) Experimental, fitted and cross-validation concentration profile for the dissolution of 

${ }^{\circ} \mathbf{C}$.

4 The same experimental, fitted and cross-validation concentrations are shown in Figure 5 for 5 the dissolution of form II, in Figure 6 for the growth of form I and, finally, in Figure 7 for the 6 growth of form II. The simulated concentrations for the dissolution of both forms seem to 7 follow well the experimental values and the 95\% confidence interval for all the estimated 8 values are narrow (as shown in the third and fourth column of Table 3).

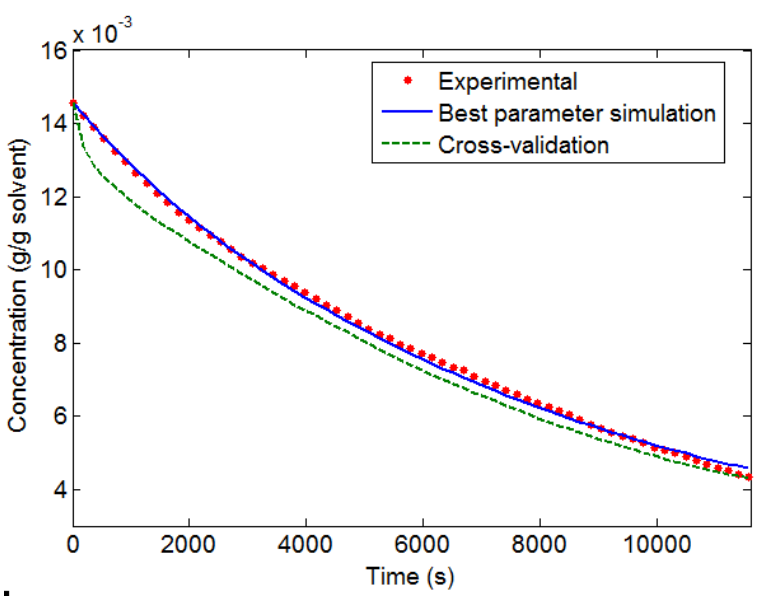

(a)

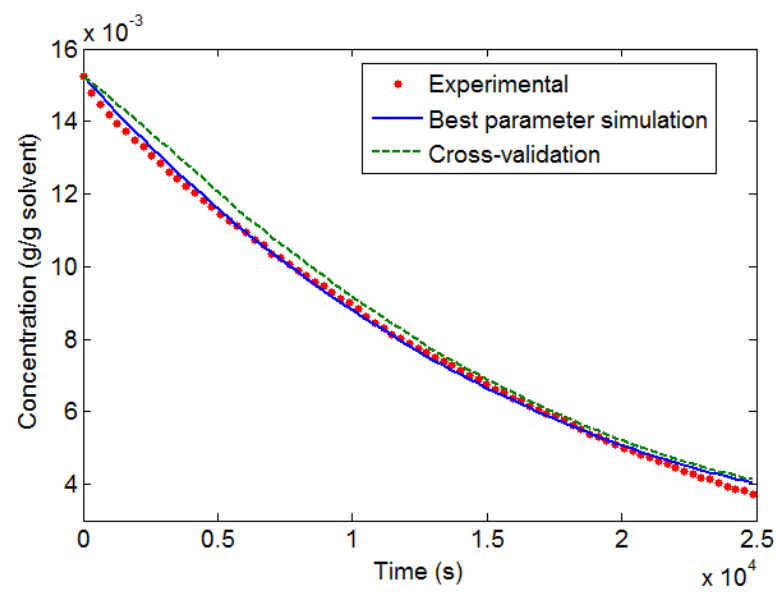

(b)

12 Figure 6: Growth experiments for form I: (a) Experimental, fitted and cross-validation concentration profile for the 13 growth of form $\mathrm{I}$ in a desupersaturation experiment performed with $-\mathbf{0 . 1}{ }^{\circ} \mathrm{C} / \mathrm{min}$ cooling rate (b) Experimental, fitted and cross-validation concentration profile for the growth of form $I$ in a desupersaturation experiment performed with $-0.05^{\circ} \mathrm{C} / \mathrm{min}$ cooling rate.

17 The cross validation still follows reasonably well the experimental data with the exception of 18 the dissolution of form I at 10 and $35^{\circ} \mathrm{C}$ (see Figure $4 \mathrm{a}$ and d). In these two cases, the trends of the cross-validation concentration slightly differ from the experimental values. There are two possible reasons for this behaviour; the first is simply the approximation of the crystal 
1 size distribution to a Gaussian function that might generate an error in the evaluation of the

2 initial crystal size distribution for these two specific experiments. The second reason might be

3 a reduced sensitivity to the temperature change during the estimation performed leaving out

4 the highest and lowest temperatures, due to the smaller temperature range in which the

5 parameters are calculated $\left(20\right.$ and $15{ }^{\circ} \mathrm{C}$ instead of $25{ }^{\circ} \mathrm{C}$ for the cross-validation of the

6 experiments at 15 and $25{ }^{\circ} \mathrm{C}$ ). Figure 6a also shows a deviation of the calculated cross-

7 validation concentration from the experimental values, especially at the beginning of the

8 profile. In this case, the difference is most certainly due to an experimental error on the

9 determination of the initial crystal size distribution or to the approximation of the distribution

10 itself with a Gaussian function, as the deviation is located close to the initial period.
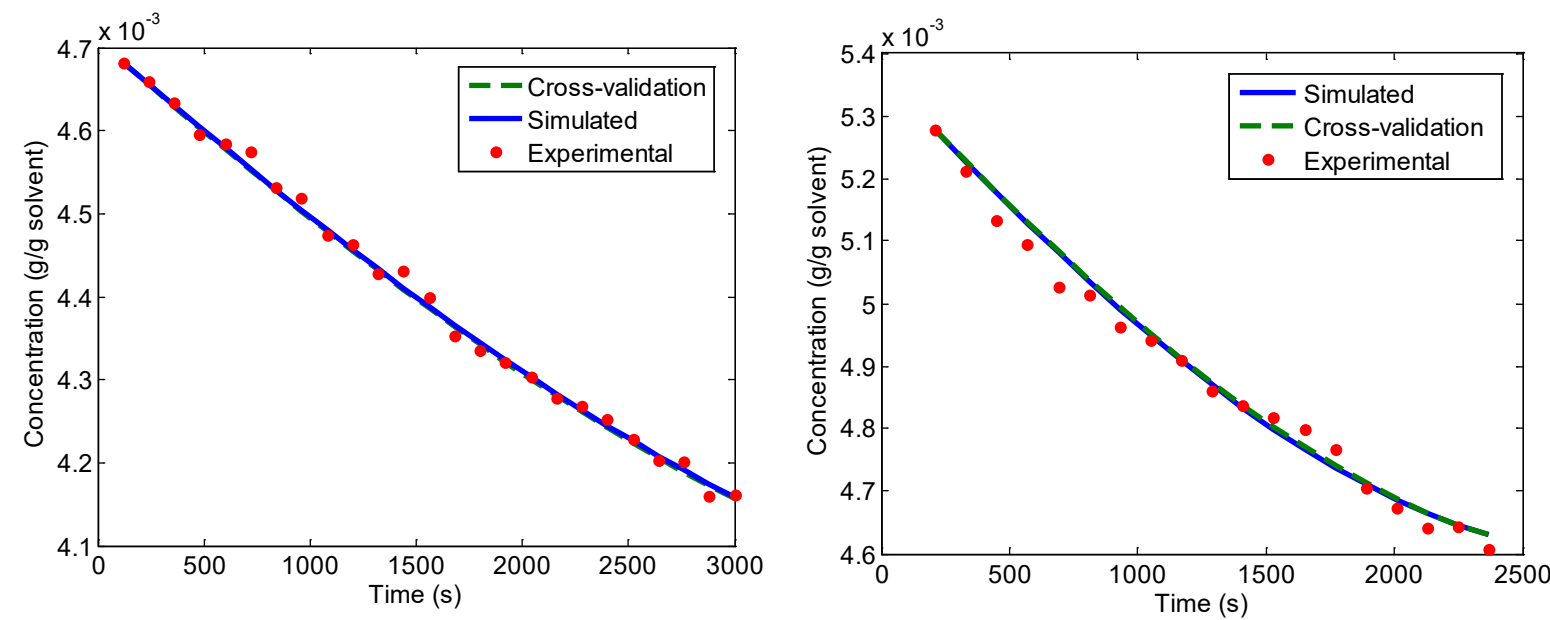

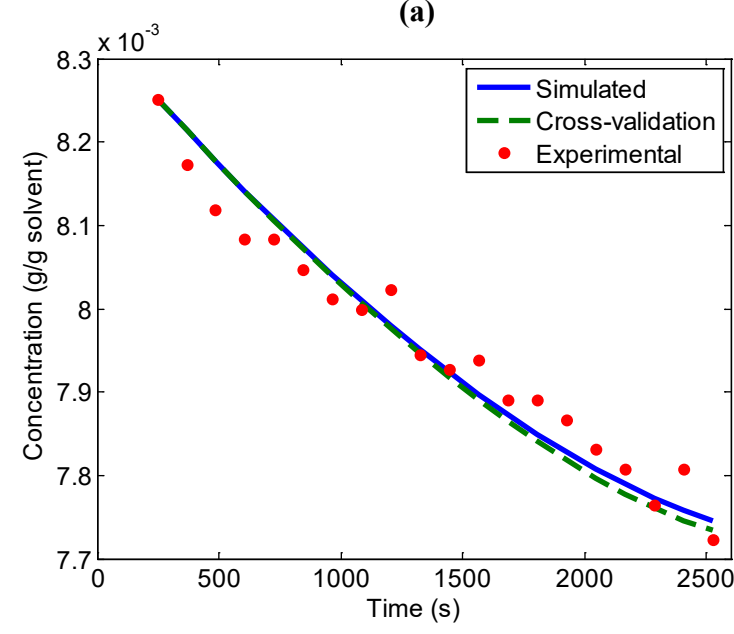

(c)

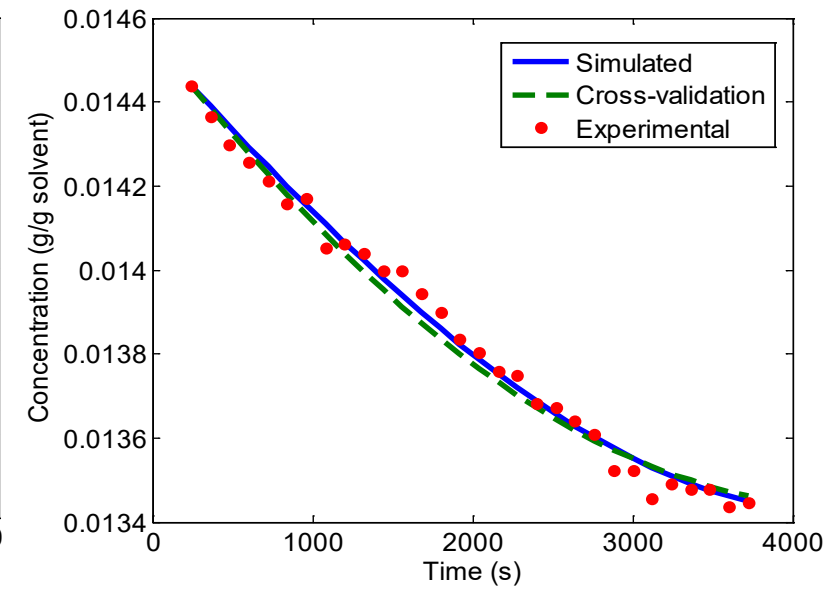

(d) 
1 Figure 7: Growth experiments for form II: (a) Experimental, fitted and cross-validation concentration profile for the 2 growth of form II at $10{ }^{\circ} \mathrm{C}$ (b) Experimental, fitted and cross-validation concentration profile for the growth of form 3 II at $15{ }^{\circ} \mathrm{C}$ (c) Experimental, fitted and cross-validation concentration profile for the growth of form II at $25{ }^{\circ} \mathrm{C}$ (d)

4 Experimental, fitted and cross-validation concentration profile for the growth of form II at $35^{\circ} \mathrm{C}$. 5

6 However, the presence of an estimation error due to an imprecise initial crystal size 7 distribution is not surprising considering how difficult is to obtain good and reliable 8 measurement of the crystal size distribution with standard techniques such as the Malvern 9 Mastersizer or 2D image analyses ( $\mathrm{Su}$ et al. 2017; Ma et al. 2016). Figure 8 shows the 10 simulated primary and secondary nucleation for form I. 

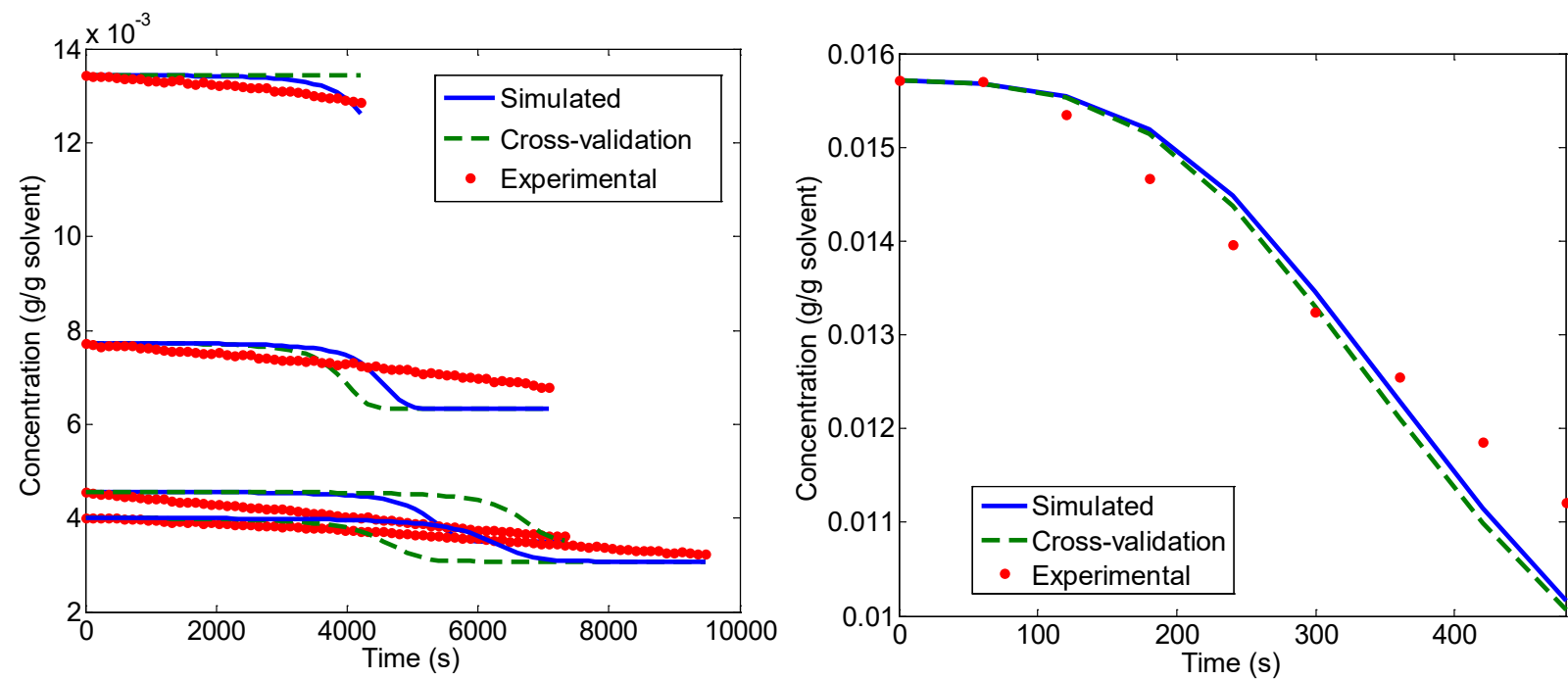

(a)

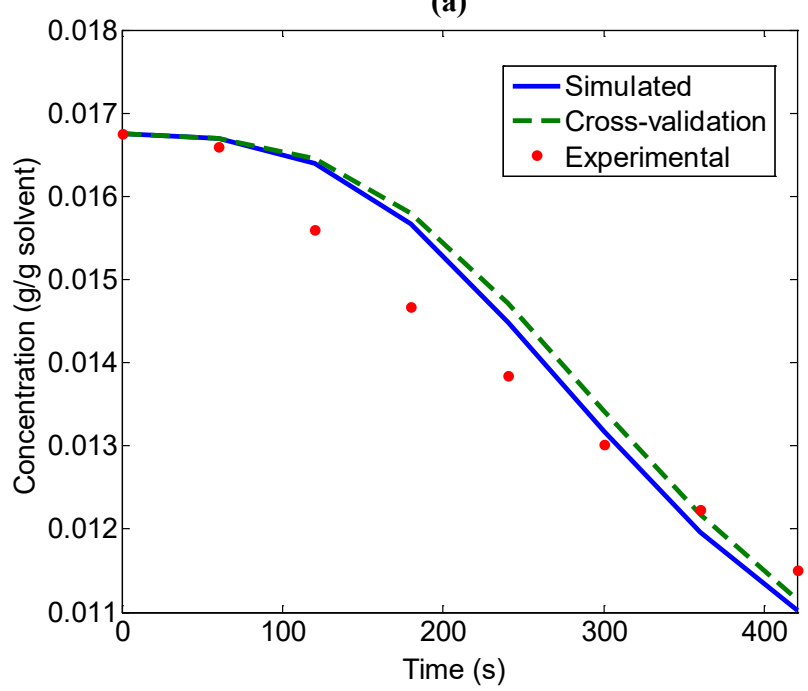

(c)

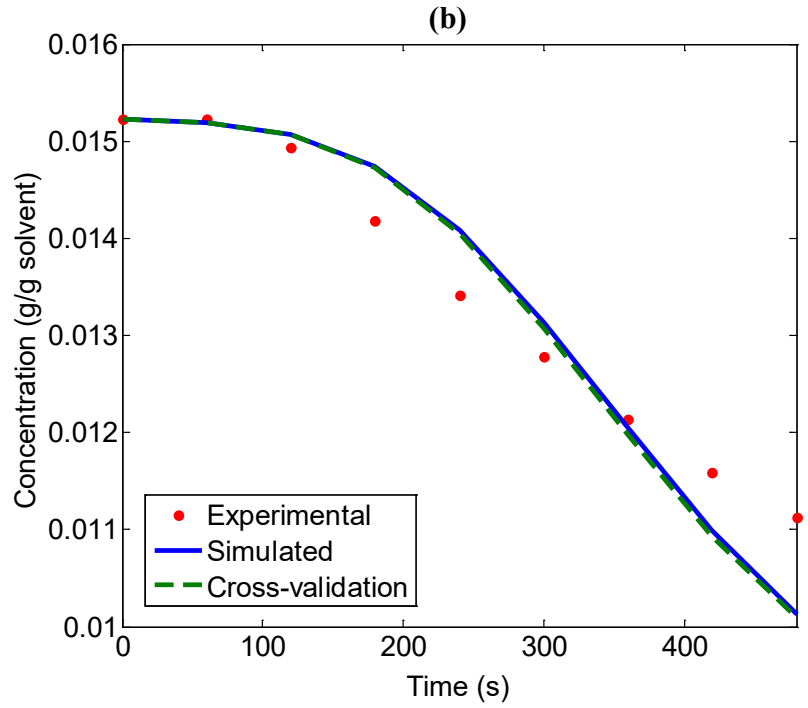

(d)

Figure 8: (a) Secondary nucleation of form I during transformation (four isothermal experiments): continuous line is simulated and dots are experimental data $(b, c, d)$. Primary nucleation of form $I$ after seeding (three experiments, similar conditions): continuous line is simulated and dots are experimental data.

2 The difference between simulated and experimental concentration is higher compared to the

3 experiments with growth and dissolution of both forms and the $95 \%$ confidence intervals are

4 also broader (as shown in Table 3). This is due to the difficulty in estimating the kinetics

5 parameters for a stochastic process such as nucleation and also because of the limited number

6 of experimental data available. 
1 One of the APFC experiments performed (Simone et al. 2014) was used to validate the set of

2 parameters estimated. Seeding and dissolution cycle were simulated using the initial 3 conditions shown in Table 4.

4

Table 4: Initial conditions for the model validation shown in Figure 9 and 10.

\begin{tabular}{ll}
\hline Validation initial conditions parameters & Value \\
\hline Seeding temperature $\left[{ }^{0} \mathrm{C}\right]$ & 37.26 \\
\hline Solute concentration $\left[\frac{\mathrm{g}}{\mathrm{g} \text { solvent }}\right]$ & 0.0151 \\
\hline Mass of seed crystals $[\mathrm{g}]$ & 0.61 \\
\hline Form II in the seed crystals $[\% \mathrm{w} / \mathrm{w}]$ & 60 \\
\hline Mass of solvent $[g]$ & 400 \\
\hline Form I sigma, $\sigma_{I}[\mu \mathrm{m}]$ & 6 \\
\hline Form I mean, $\mu_{I}[\mu \mathrm{m}]$ & 69 \\
\hline Form II sigma, $\sigma_{I I}[\mu m]$ & 225 \\
\hline Form II mean, $\mu_{I I}[\mu m]$ & 75 \\
\hline
\end{tabular}

6

7 The mean $\mu$ and the sigma $\sigma$ of the crystal size distribution for the validation experiment were

8 estimated as follows:

$9 \quad \mu=\frac{L_{\max }+L_{\min }}{2}$

$10 \sigma=\frac{L_{\max }-L_{\min }}{2}$

11 where $L_{\max }$ and $L_{\min }$ are the maximum and minimum sizes of the sieves used to separate the

12 seeds (the Malvern Mastersizer was not used for this sample).

13 The results of the validation experiment are shown in Figure 9 and 10. 


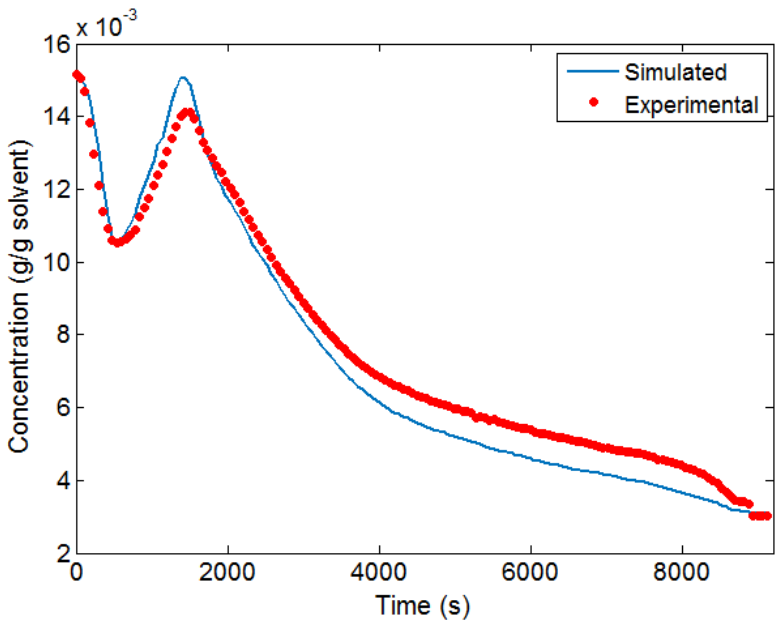

2 Figure 9: Model validation: experimental and simulated data for an APFC experiment. Temperature plotted with experimental and simulated concentrations.

5 Despite the difficulty in obtaining a good estimation for the nucleation kinetics the simulated 6 concentration for the validation experiments correctly follows the experimental data and the 7 trend of the first moment of form II is similar to the corresponding Raman signal. A 8 discrepancy is present in the cooling section and it is probably due to the uncertainty in the 9 estimation of primary nucleation (the simulated first moment of form I is higher than the 10 actual one, and therefore, the growth is overestimated). However, the maximum percentage 11 error on the concentration measurement is around $16 \%$ and it is localized in the cooling 12 section, and the time of complete dissolution of the undesired form is calculated correctly. 


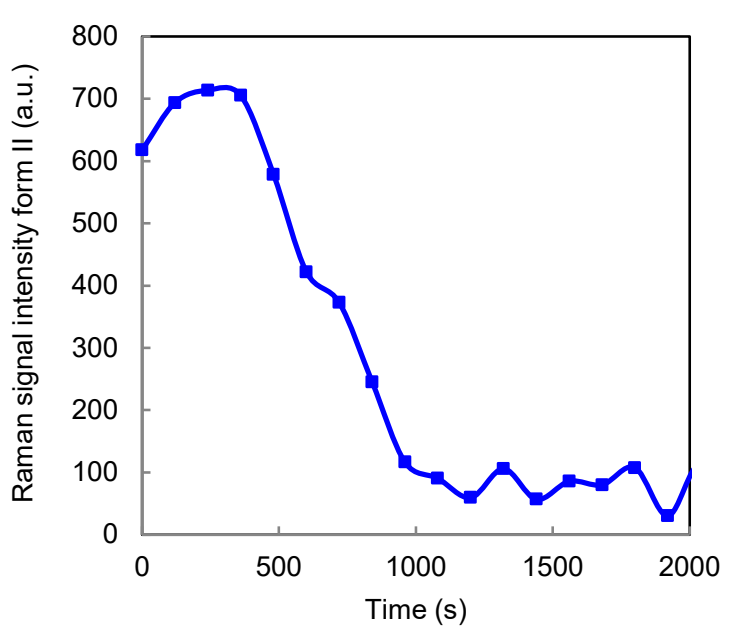

(a)

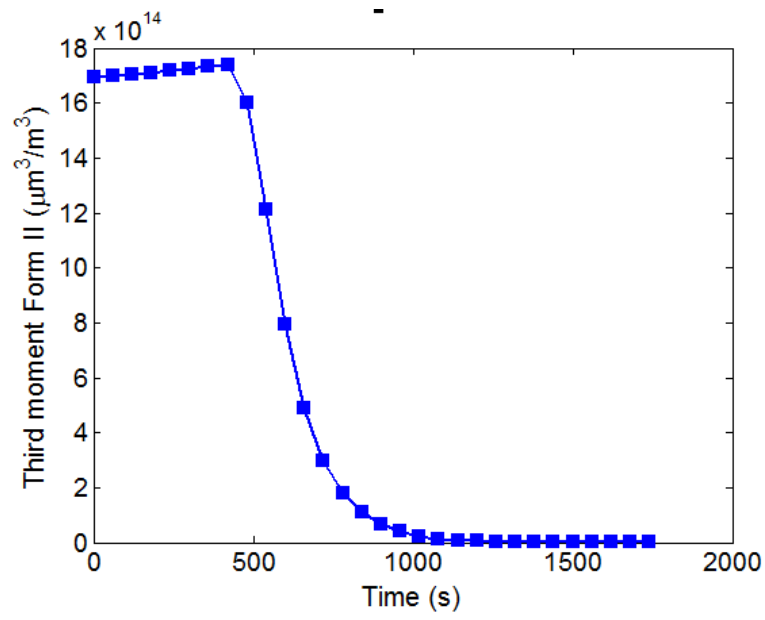

(c)

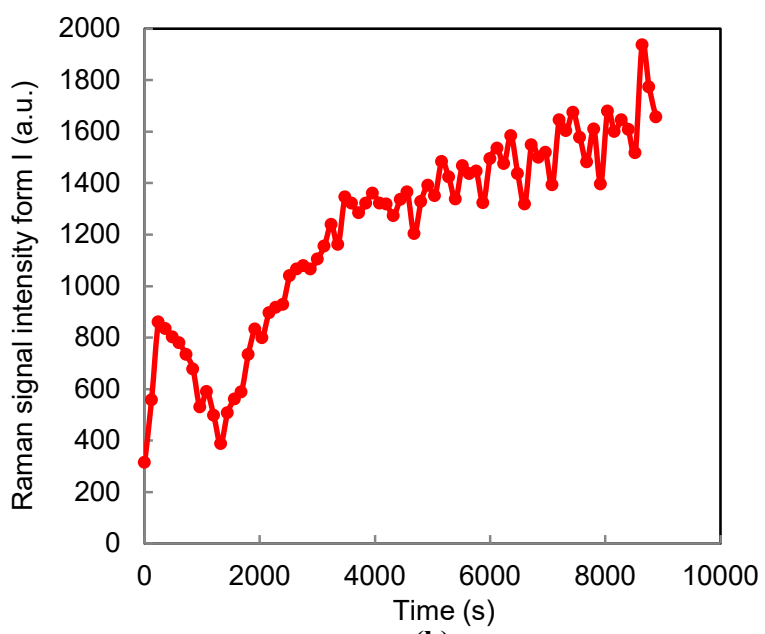

(b)

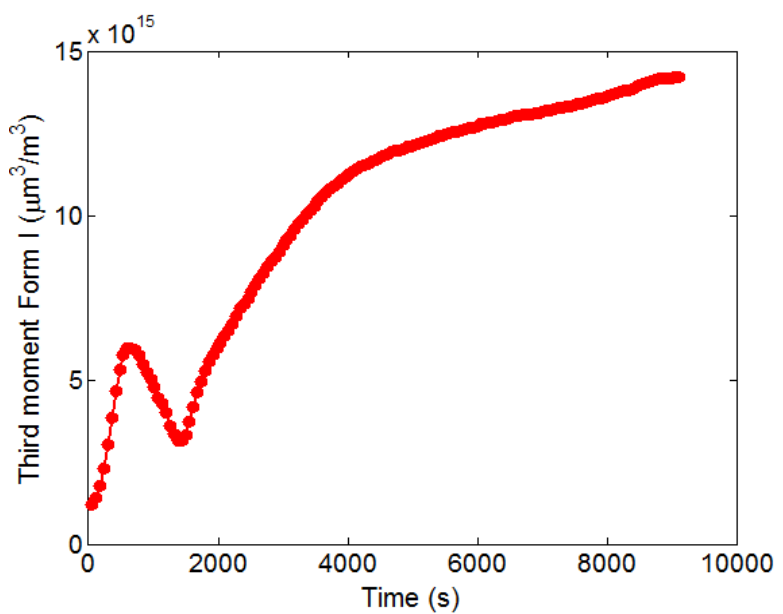

(d)

2

3

6 Figure 10 shows the third moments of form I and II compared to the Raman signals of the

Figure 10: Model validation: experimental and simulated data for an APFC experiment. Raman signal intensities for form I and II during the experiment (a and b) compared to the simulated third moment of both polymorphs.

specific peaks of those forms. The Raman intensity is proportional with the amount of solid in suspension and, therefore, can be directly compared with the third moments of the polymorphs. In fact, the third moment of the distribution $\left(\mu_{3}\right)$ is proportional to the specific volume of crystal population $\left(V_{c}\right)$ and is one of the infinite moments of CSD, generally defined as: 


$$
\mu_{\mathrm{k}}=\int_{0}^{\infty} L^{\mathrm{k}} f(L, t) d L \rightarrow V_{c}=k_{v} \mu_{3}
$$

2 This means that the model is able to simulate and predict well the APFC dissolution cycle so

3 it is suitable for optimization. Form II slightly grows during the first seconds after seeding and

4 then is dissolved by the heating cycle. The amount of form I increases because of nucleation,

5 then decreases during the dissolution cycle because of partial dissolution of form I with form

$6 \quad$ II and then increases again due to growth.

\subsection{Process optimization for polymorphic crystallization}

9 Optimization was performed using the kinetic parameters to find the optimal temperature profile that eliminates form II and maximizes the size of the crystals of form I at the end of

11 the batch. The batch time was discretized in fifty time intervals of equal duration and the

12 temperature profile optimization was performed by applying the ES-CMA global optimization

13 algorithm. The results were further refined by performing a second optimization using the

14 global optimizer's crude optimum as starting point, applying the Matlab fmincon function

15 (SQP algorithm). The initial temperature of seeding was fixed at around $37{ }^{\circ} \mathrm{C}$. The problem

16 is formulated as follows:

$17 \min _{T(k)}\left(-\bar{L}_{I, \text { end }}\right)$

18 Subject to:

$19-0.5 \leq \frac{d T}{d t} \leq 0.5$

$20 \quad 11 \leq T \leq 45$ 
$1 \quad C_{\text {end }} \leq C_{\text {max }, \text { end }}=0.005 \mathrm{~g} / \mathrm{g}$ solvent

$2 \quad \mu_{I I 1, \text { end }}=0$

3 where $T$ is the temperature defined in ${ }^{\circ} \mathrm{C}, \frac{d T}{d t}$ the heating/cooling rates in ${ }^{\circ} \mathrm{C} / \mathrm{min}, C_{\text {end }}$ the

4 solute concentration at the end of the batch ( $\mathrm{g} / \mathrm{g}$ solvent) and $\mu_{I I 1, \text { end }}$ the second moment of 5 form II at the end of the batch.

6 A 20 minutes stabilization time was applied: the final temperature was kept constant to allow

7 the consumption of the remained supersaturation. The initial conditions used for the 8 optimization are shown in Table 5.

9

Table 5: Initial conditions for the optimization.

\begin{tabular}{ll}
\hline Validation initial conditions parameters & Value \\
\hline Seeding temperature $\left[{ }^{0} \mathrm{C}\right]$ & 37.26 \\
\hline Solute concentration $\left[\frac{g}{g \text { solvent }}\right]$ & 0.015 \\
\hline Mass of solid $[g]$ & 0.6 \\
\hline Form II in the seed crystals $[\% w / w]$ & 40 \\
\hline Mass of solvent $[g]$ & 400 \\
\hline Form I sigma, $\sigma_{I}[\mu m]$ & 10 \\
\hline Form I mean, $\mu_{I}[\mu m]$ & 50 \\
\hline Form II sigma, $\sigma_{I I}[\mu m]$ & 10 \\
\hline Form II mean, $\mu_{I I}[\mu m]$ & 50 \\
\hline
\end{tabular}

11

12 The results of the optimization (shown in Figure 11a to c) demonstrate that a heating step is

13 not only required to eliminate form II but also allows larger crystal size of form I at the end of

14 the batch: imposing only cooling in the optimization code $\left(-0.5^{\circ} \frac{C}{\min } \leq \frac{d T}{d t} \leq-0.001^{\circ} \mathrm{C} /\right.$ 
$1 \mathrm{~min}$ ) resulted in lower crystal size, although all the metastable form naturally converted to the

2 stable one by the end of the batch.

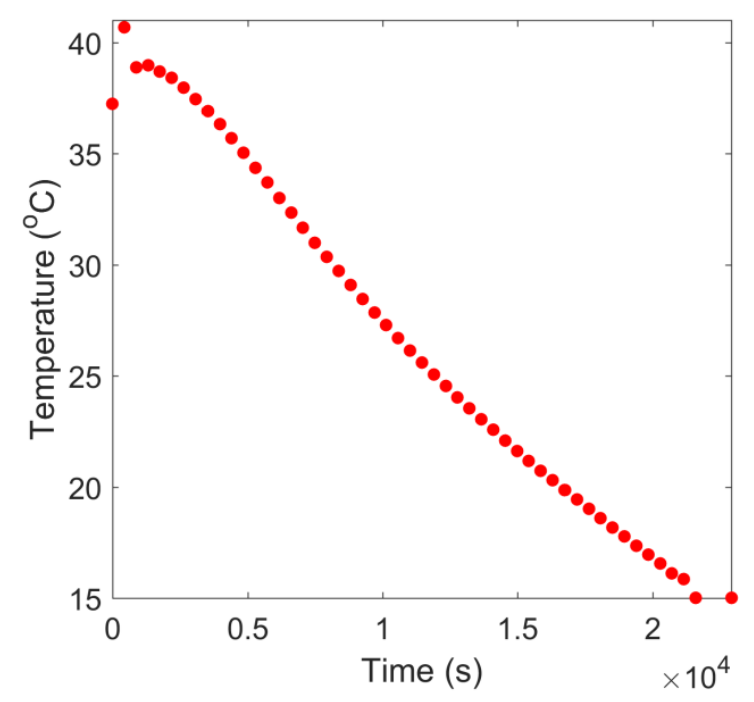

(a)

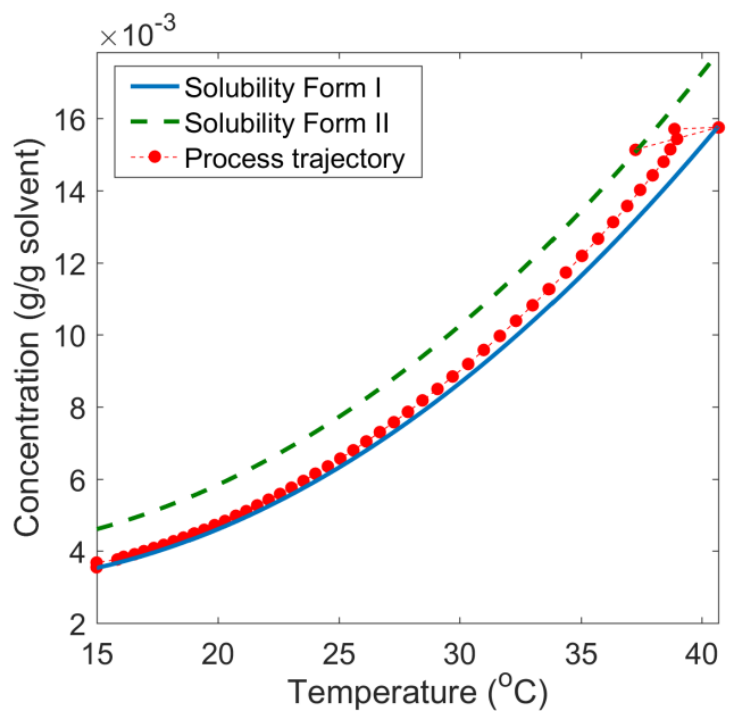

(b)

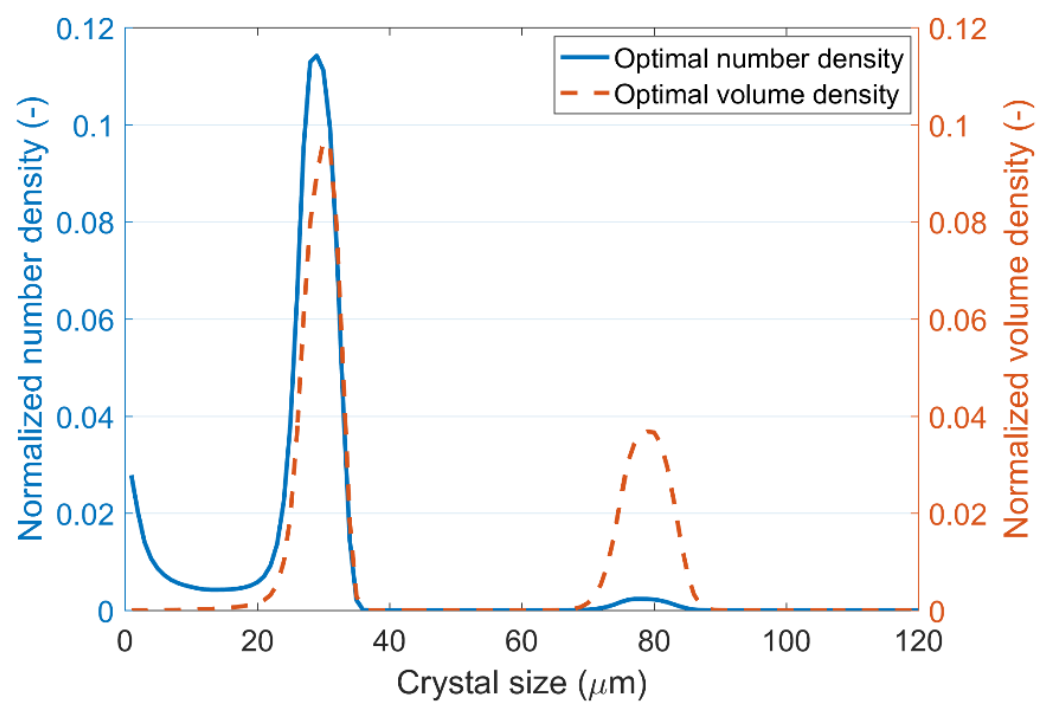

(c)

Figure 11: (a) Optimal temperature profile plotted against time; (b) Optimal operating trajectory plotted in the phase 
1 The value of the objective function calculated was quite low compare to experimental results

$2 \quad\left(\frac{\mu_{1, \text { Iopt }}}{\mu_{0, \text { Iopt }}}=26.5 \mu \mathrm{m}\right.$, corresponding to a $\frac{\mu_{4, \text { Iopt }}}{\mu_{3, \text { Iopt }}}=44.9 \mu \mathrm{m}$ versus around $100-150 \mu \mathrm{m}$ obtained

3 experimentally at the end of the batch) but this most probably is due to the uncertainty of the

4 parameters estimated for nucleation of form I. The heating step at the very beginning of the

5 optimal temperature profile is not only has the effect of dissolving form II, but it is also

6 beneficial to improve the crystal size distribution of form I.

7 The presence of heating steps in optimized batch crystallization processes was already found

8 by other authors (Majumder, Nagy 2013; Qamar et al. 2010; Yeom et al. 2013; Nagy et al.

9 2011) as a result of the inclusion of the dissolution kinetics in the PBEs. In those cases

10 heating can correct a non-optimal seeding and allows a better final CSD. After the heating

11 step in the optimal profile calculated in this work the temperature is kept high in order to 12 allow growth of the form I crystal and then drops in the end to reach the desired yield. Figure

$1311 \mathrm{~b}$ shows the optimized temperature profile in the phase diagram: the solute concentration is

14 kept below the solubility of the metastable form to avoid its further nucleation and above the solubility of the stable form to allow its growth during the cooling phase.

\section{Conclusions}

The active polymorphic feedback control (APFC) is a strategy that detects and eliminates the metastable polymorph after nucleation of a mixture or contaminated seeding (Simone et al. 2014). The approach uses a combination of Raman spectroscopy to detect the metastable

21 polymorph and trigger a dissolution cycle to eliminate it, and then applies ATR-UV/Vis spectroscopy to grow the remaining crystals of the stable form through supersaturation control. Despite being very efficient in obtaining the pure stable polymorph, this model-free control does not lead to optimal crystal size distribution of the product of stable polymorph at 
1 the end of the batch. In fact, the size distribution of the crystals of the stable form after the

2 dissolution cycle is not controlled and it might not be the optimal to allow a good quality CSD

3 at the end of the supersaturation control. For this reason a model-based active polymorphic

4 control (mbAPC), that allows both the elimination of the metastable form and larger crystals

5 of the stable form at the end of the batch, was developed. The kinetic parameters that are

6 needed to describe the mbAPC for ortho-aminobenzoic acid (dissolution and growth of form I

7 and II, secondary nucleation of form I) were estimated and validated using the data from

8 seeded experiments. A specific design of experiments was performed to estimate each

9 parameter separately and therefore, to avoid correlations between them, as well as to simplify

10 the parameter estimation. All the parameters estimated presented a narrow $95 \%$ confidence

11 interval, apart from the nucleation of the stable form, probably because of the stochastic

12 nature of this phenomenon.

13 After the parameter estimation, optimization was performed. It was found that the dissolution 14 cycle, normally induced by the APFC, not only allows the elimination of the metastable form 15 II, but it is also beneficial to obtain larger crystals of form I at the end of the batch. This is in 16 accordance with experiments as well as with the results of other optimization studies where 17 dissolution was included in the model.

18 In conclusion, the proposed mbAPC can be useful for the design of batch crystallization 19 processes of polymorphic systems as it allows obtaining large crystals of the stable form, even 20 in case of in situ nucleation of a mixture of the stable and metastable polymorphs or erroneous 21 seeding. 


\section{Acknowledgements}

2 Financial support provided by the European Research Council grant no. [280106-CrySys] is 3 acknowledged.

$5 \quad$ References

6 Alatalo, H., Hatakka, H., Kohonen, J., Reinikainen, S.P., Louhi-Kultanen, M. 2010, "Process

7 control and monitoring of reactive crystallization of L-glutamic acid", AIChE Journal, vol. 8 56, no. 8, pp. 1063-2076.

9 Beckmann, W. 2000, "Seeding the desired polymorph: background, possibilities, limitations, 10 and case studies", Organic Process Research and Development, vol. 4, pp. 372-383.

11 Besenhard, M.O., Chaudhury, A., Vetter, T., Ramachandran, R., Khinast, J.G. 2015, 12 "Evaluation of Parameter Estimation Methods for Crystallization Processes Modeled via 13 Population Balance Equations", Chemical Engineering Research and Design, vol. 94, pp. $14 \quad 275-289$.

15 Cardew, P.T., Davey, R.J. 1985, "The kinetics of solvent-mediated phase transformations" 16 Proceedings of the Royal Society A, vol. 398, pp. 415-428.

17 Chew, J.W., Black, S., Chow, P.S., Tan, R.B.H., Carpenter, K.J. 2007, "Stable polymorphs: 18 difficult to make and difficult to predict", Crystal Engineering Communications, vol. 9, pp. $19 \quad 128-130$ 
1 Cornel, J., Lindenberg, C., Mazzotti, M. 2009, "Experimental characterization and population

2 balance modeling of the polymorph transformation of L-glutamic acid", Crystal Growth and

3 Design, vol. 9, no. 1, pp. 243-252.

4 Doki, N., Seki, H., Takano, K., Asatani, H., Yukota, M., Kubota, N. 2004, "Process control of

5 seeded batch cooling crystallization of the metastable $\alpha$-form glycine using in-situ ATR-FTIR

6 spectrophotometer and an in-situ FBRM particle counter", Crystal Growth and Design, vol. 4,

7 no. 5, pp. 949-953.

8 Doki, N., Yukota, M., Kido, K., Sasaki, S., Kubota, N. 2003, "Reliable and selective

9 crystallization of the metastable $\alpha$-form glycine by seeding", Crystal Growth and Design, vol.

10 4, no. 1, pp. 103-107.

11 Fevotte, G., Caillet, A., Nida, S.O. 2007, "A population balance model of the solution-

12 mediated phase transition of citric acid", AIChE J., vol. 53, no. 10.

13 Gunawan R., Fusman I., Braatz R.D. 2004, "High Resolution Algorithms for

14 Multidimensional Population Balance Equations", AIChE Journal, vol. 50, no. 14, pp. 2738 152749.

16 Hansen, N., Mueller, S.D., Koumoutsakos, P. 2003, "Reducing the Time Complexity of the 17 Derandomized Evolution Strategy with Covariance Matrix Adaptation (CMA-ES) ", 18 Evolutionary Computation., vol. 11, no. 1, pp. 1-18.

19 Hermanto, M.W., Braatz, R.D., Chiu, M.S. 2011, "Integrated batch-to-batch and nonlinear 20 model predictive control for polymorphic transformation in pharmaceutical crystallization", 21 AIChE Journal, vol. 57, no. 4, pp. 1008-1019. 
1 Hermanto, M.W., Chiu, M.S., Braatz, R.D. 2009, "Nonlinear model predictive control for the 2 polymorphic transformation of L-glutamic acid crystals", AIChE Journal, vol. 55, no. 10, pp. $32631-2645$.

4 Hermanto, M.W., Chiu, M.S., Woo, X.Y., Braatz, R.D. 2007, "Robust Optimal Control of 5 Polymorphic Transformation in Batch Crystallization", AIChE Journal, vol. 53, no. 10.

6 Jiang, S., ter Horst, J.H., Jansens, P.J. 2010a, "Control over polymorph formation of o7 aminobenzoic acid", Crystal Growth and Design, vol. 10, pp. 2541-2547.

8 Jiang, S., ter Horst, J.H., Jansens, P.J. 2010b, "Mechanism and kinetics of polymorphic 9 transformation of o-aminobenzoic acid", Crystal Growth and Design, vol. 10, pp. 2123-2128.

10 Jiang, S., ter Horst, J.H., Jansens, P.J. 2008, "Concomitant polymorphism of o-aminobenzoic 11 acid in antisolvent crystallization", Crystal Growth and Design, vol. 8, no. 1, pp. 37-43.

Kobari, M., Kubota, N., Hirasawa, I. 2014, "A population balance model for solvent-mediated polymorphic transformation in unseeded solutions", Crystal Engineering Communications,

Kee, N., Tan, R.B.H., Braatz, R.D. 2009, "Selective crystallization of the metastable a-form of the L-glutamic acid using concentration feedback control", Crystal Growth and Design, vol. 9, no. 7, pp. 3044-3051.

Kee, N.C., Arendt, P.D., Tan, R.B.H., Braatz, R.D. 2009, "Selective crystallization of the metastable anhydrate form in the enantiotropic pseudo-dimorph system of L-phenilalanine using concentration feedback control", Crystal Growth and Design, vol. 9, no. 7, pp. 30523061. vol. 16, pp. 6049-6058. 
1 Lai, T.C., Cornevin, J., Ferguson, S., Li, N., Trout, B.L., Myerson, A.S. 2015, "Control of 2 polymorphism in continuous crystallization via mixed suspension mixed product removal 3 systems cascade design", Crystal Growth and Design, vol. 15, no. 7, pp. 3374-3382.

4 Ma, C.Y., Liu, J.J., Wang, X.Z. 2016, "Measurement, modelling, and closed-loop control of 5 crystal shape distribution: Literature review and future perspectives", Particuology, vol. 26, 6 pp. $1-18$.

7 Majumder, A., Nagy, Z.K. 2013, "Fines removal in a continuous plug flow crystallizer by 8 optimal spatial temperature profiles with controlled dissolution", AIChE Journal, vol. 59, no. $9 \quad 12$, pp. 4582-4594.

10 Minamisono, T., Takiyama, H. 2013, "Control of polymorphism in the anti-solvent 11 crystallization with a particular temperature profile", Journal of Crystal Growth, vol. 362, pp. $12 \quad 135-139$.

13 Nagy, Z.K., Aamir, E., Rielly, C.D. 2011, "Internal fines removal using a population balance 14 model based control of crystal size distribution under dissolution, growth and nucleation 15 mechanisms", Crystal Growth and Design, vol. 11, pp. 2205-2219.

16 Ono, T., Kramer, H.J.M., Ter Horst, J.H., Jansens, P.J. 2004, "Process modeling of the 17 polymorphic transformation of L-glutamic acid", Crystal Growth and Design, vol. 4, no. 6, 18 pp. 1161-1167.

19 Qamar, S., Mukhtar, S., Seidel-Morgenstern, A. 2010, "Efficient solution of a batch 20 crystallization model with fines dissolution", Journal of Crystal Growth, vol. 312, pp. 2936212945. 
1 Qu, H., Alatalo, H., Hatakka, H., Kohonen, J., Louhi-Kultanen, M., Reinikainen, S., Kallas, J.

2 2009, "Raman and ATR FTIR spectroscopy in reactive crystallization: Simultaneous

3 monitoring of solute concentration and polymorphic state of the crystals", Journal of Crystal

4 Growth, vol. 311, no. 13, pp. 3466-3475.

5 Scholl, J., Bonalumi, D., Vicum, L., Mazzotti, M. 2006, "In situ monitoring and modeling of 6 the solvent-mediated polymorphic transformation of L-glutamic acid", Crystal Growth and 7 Design, vol. 6, no. 4, pp. 881-891.

8 Sheikholeslamzadeh, E., Rohani, S. 2013, "Modeling and optimal control of solution 9 mediated polymorphic transformation of L-glutamic acid", Industrial and Engineering 10 Chemistry Research, vol. 52, no. 2633, pp. 2641.

11 Simone, E., Saleemi, A.N., Nagy, Z.K. 2014, "Active Polymorphic Feedback Control of 12 Crystallization Processes Using a Combined Raman and ATR-UV/Vis Spectroscopy 13 Approach", Crystal Growth and Design, vol. 14, no. 4, pp. 1839-1850.

14 Su, Q., Rielly, C.D., Powell, K.A., Nagy, Z.K. 2017, "Mathematical modelling and experimental validation of a novel periodic flow crystallization using MSMPR crystallizers", AIChE Journal, vol. 63, pp. 1313-1327.

17 Szilagyi, B., Nagy, Z.K. 2016, “Graphical Processing Unit (GPU) Acceleration for Numerical 18 Solution of Population Balance Models Using High Resolution Finite Volume Algorithm", 19 Computers and Chemical Engineering, vol. 91, pp. 167-181.

20 Threlfall, T. 2000, "Crystallization of polymorphs: thermodynamic insight into the role of 21 solvent", Organic Process Research and Development, vol. 4, pp. 384-390. 
1 Trifkovic, M., Rohani, S., Sheikhzadeh, M. 2012, " Kinetics estimation and polymorphic

2 transformation modeling of Buspirone hydrochloride", Journal of Crystallization Process and

3 Technology, vol. 2, pp. 31-43.

4 Wantha, L., Flood, A., 2013, "Population balance modeling of the solution-mediated

5 transformation of DL-Methionine polymorphs", Chemical Engineering and Technology, vol.

$6 \quad 36$, no. 8 , pp. 1313-1319.

7 Yeom, S., Yun, H., Yang, D.R. 2013, "Optimization of temperature swing strategy for

8 selective cooling crystallization of $\alpha$-form L-glutamic acid crystals", Korean J. Chem. Eng.,

9 vol. 30, no. 10, pp. 1836-1842.

10

11 